\title{
The Roles of the Dystrophin-Associated Glycoprotein Complex at the Synapse
}

\author{
Gonneke S. K. Pilgram • Saranyapin Potikanond • \\ Richard A. Baines - Lee G. Fradkin • \\ Jasprina N. Noordermeer
}

Received: 24 August 2009/Accepted: 15 October 2009/Published online: 9 November 2009

(C) The Author(s) 2009. This article is published with open access at Springerlink.com

\begin{abstract}
Duchenne muscular dystrophy is caused by mutations in the dystrophin gene and is characterized by progressive muscle wasting. A number of Duchenne patients also present with mental retardation. The dystrophin protein is part of the highly conserved dystrophin-associated glycoprotein complex (DGC) which accumulates at the neuromuscular junction (NMJ) and at a variety of synapses in the peripheral and central nervous systems. Many years of research into the roles of the DGC in muscle have revealed its structural function in stabilizing the sarcolemma. In addition, the DGC also acts as a scaffold for various signaling pathways. Here, we discuss recent advances in understanding DGC roles in the nervous system, gained from studies in both vertebrate and invertebrate model systems. From these studies, it has become clear that the DGC is important for the maturation of neurotransmitter receptor complexes and for the regulation of neurotransmitter release at the NMJ and central synapses. Furthermore, roles for the DGC have been established in consolidation of long-term spatial and recognition memory. The challenges ahead include the integration of the behavioral and mechanistic studies and the use of this information to identify therapeutic targets.
\end{abstract}

Gonneke S. K. Pilgram and Saranyapin Potikanond contributed equally to this work.

G. S. K. Pilgram • S. Potikanond • L. G. Fradkin $(\bowtie) \cdot$

J. N. Noordermeer $(\square)$

Laboratory of Developmental Neurobiology, Department

of Molecular and Cell Biology, Leiden University Medical Center,

Einthovenweg 20, P.O. Box 9600, 2300 RC Leiden,

The Netherlands

e-mail: L.G.Fradkin@lumc.nl

e-mail: J.N.Noordermeer@lumc.nl

R. A. Baines

Faculty of Life Sciences, University of Manchester,

Manchester M13 9PT, UK
Keywords Dystrophin · DGC · NMJ · CNS · PNS · Retina . Duchenne muscular dystrophy $\cdot$ Mammals $\cdot$ Drosophila .

C. elegans

\begin{tabular}{|c|c|}
\hline \multicolumn{2}{|c|}{ Abbreviations } \\
\hline $\mathrm{ACh}$ & Acetylcholine \\
\hline $\mathrm{AChR}$ & Acetylcholine receptor \\
\hline Akt & Protein kinase B \\
\hline BMP & Bone morphogenetic protein \\
\hline $\mathrm{Ca}^{2+}$ & Calcium ion \\
\hline CaMKII & $\mathrm{Ca}^{2+} /$ calmodulin-dependent protein kinase II \\
\hline cGMP & Cyclic guanosine monophosphate \\
\hline CNS & Central nervous system \\
\hline DGC & Dystrophin-associated glycoprotein complex \\
\hline DMD & Duchenne muscular dystrophy \\
\hline EPSP & Excitatory postsynaptic potential \\
\hline ERG & Electroretinogram \\
\hline GABA & $\gamma$-Aminobutyric acid \\
\hline Grb2 & Growth factor receptor-bound protein 2 \\
\hline ILM & Inner limiting membrane \\
\hline InR & Insulin receptor \\
\hline IPSC & Inhibitory postsynaptic current \\
\hline IPSP & Inhibitory postsynaptic potential \\
\hline LTD & Long-term depression \\
\hline LTP & Long-term potentiation \\
\hline MAPK & Mitogen-activated protein kinase \\
\hline mEPSP & Miniature EPSP \\
\hline mIPSC & Miniature IPSC \\
\hline mIPSP & Miniature IPSP \\
\hline MuSK & Muscle-specific kinase \\
\hline NMJ & Neuromuscular junction \\
\hline nNOS & Neuronal nitric oxide synthase \\
\hline NO & Nitric oxide \\
\hline NOS & Nitric oxide synthase \\
\hline OPL & Outer plexiform layer \\
\hline
\end{tabular}




$\begin{array}{ll}\text { PI3K } & \text { Phosphoinositide 3-kinases } \\ \text { PKA } & \text { Protein kinase A } \\ \text { PKC } & \text { Protein kinase C } \\ \text { PKG } & \text { Protein kinase G } \\ \text { POMT1/2 } & \text { Protein } O \text {-mannosyltransferase } 1 \text { or } 2 \\ \text { PPF } & \text { Paired-pulse facilitation } \\ \text { STD } & \text { Short-term depression } \\ \text { STP } & \text { Short-term potentiation } \\ \text { UGC } & \text { Utrophin-associated glycoprotein complex } \\ \text { utrn } & \text { Utrophin } \\ \text { VNC } & \text { Ventral nerve cord }\end{array}$

\section{Introduction}

Duchenne muscular dystrophy (DMD) is a common $\mathrm{X}$ linked, fatal genetic disorder characterized by progressive muscle wasting [1]. The disease was named after the French neurologist G.B.A. Duchenne who, in the mid1800 s, described patients that suffered not only from muscular dystrophy but also from mental retardation [2]. A major advancement in understanding the underlying cause of DMD came in 1987, when dystrophin was identified as the protein that is absent in DMD patients [3, 4]. Mental retardation occurs in approximately one third of DMD patients and is apparently dependent on the specific location of the mutation within the dystrophin gene (in mammals called the $D M D$ gene) [5]. Despite more than two decades of intense clinical and basic research into the DMD disease process and the interactions and roles of the dystrophin protein, a cure for the disease remains elusive and treatments palliative. Thus, much remains to be learned about the basic biological roles of the dystrophin protein in the musculature and in the brain.

The $D M D$ gene is one of the largest genes in the human genome, spanning $2.3 \mathrm{Mb}$ [6]. It has three upstream promoters that control expression of full-length dystrophin Dp427 and four internal promoters which regulate expression of the short dystrophin isoforms, Dp260, Dp140, Dp116, and Dp71 (reviewed at www.dmd.nl; Table 1; Textbox 1 in "Appendix"). The complexity of $D M D$ gene expression, which results in multiple transcripts and protein isoforms, has made understanding the functions of individual dystrophin protein isoforms difficult. Dp427 has an amino-terminal actin-binding domain, and Dp427, Dp260, Dp140, and Dp116 have a variable number of spectrin-like repeats that are predicted to form triple-helical rod-like structures. Dystrophin proteins invariably bear a number of protein-protein interaction domains, some of which are bound by other dystrophin-associated glycoprotein complex (DGC) members: a WW domain, a cysteine-rich region containing a ZZ domain, and a highly conserved carboxyterminal region including a coiled-coil domain.

Dystrophin is predominantly expressed in the musculature and the nervous system (Fig. 1, Table 2, and references therein). More specifically, the three distinct Dp427 variants that are transcribed from different promoters and have distinct first exons are expressed in skeletal muscle (Dp427M), throughout the brain (Dp427B) and in Purkinje cells (Dp427P), respectively. Dp260 is expressed in the retina, Dp140 in brain and kidney, Dp116 in the peripheral nervous system, and Dp71 is uniformly expressed, but most prominently present throughout the mammalian brain (reviewed in [7]; Fig. 1; Table 2). In mammals, there are two proteins which are significantly homologous to dystrophin, utrophin [8], and the much shorter dystrophinrelated protein 2 (DRP2) [9]. Utrophin is more ubiquitously expressed compared to dystrophin, hence its name. It is found in developing skeletal and smooth muscle, the nervous system, the lung, kidney, liver, spleen, and stomach $[10,11]$.

Many components of the DGC have been identified, including the dystrobrevins (DB- $\alpha$ and DB- $\beta$ ), the syntrophins $(\alpha 1, \beta 1, \beta 2, \gamma 1$, and $\gamma 2)$, dystroglycan (DG- $\alpha / \beta)$, the sarcoglycans (SG- $\alpha$, SG- $\beta$, SG- $\gamma$, SG- $\delta$, SG- $\varepsilon$, and SG$\zeta)$, and sarcospan $[10,12]$. Together with dystrophin, these proteins form a large, molecularly heterogeneous cluster [13], known as the DGC, that differs in composition depending on the tissue or organs where the components are expressed (reviewed in [10, 14-16]; Fig. 1; Table 2). The proteins of the DGC are highly conserved between species, although there are fewer homologs and isoforms in the lower vertebrates, such as zebrafish, and in the invertebrates, Caenorhabditis elegans and Drosophila (Table 1).

Due to the complex and variable composition of the DGC, it is difficult to assign a general function to this transmembrane complex. However, in all organisms studied thus far, the different DGCs localize to the plasma membrane (reviewed in [12]). In muscle, the DGC has long been thought to be required for the stabilization of the plasma membrane by linking the actin cytoskeleton to the extracellular matrix [17]. Disruption of the DGC caused by the absence of dystrophin consequently renders the sarcolemma susceptible to mechanical damage during contraction and ultimately results in muscle degeneration. More recently, it has been established that the DGC also functions as a scaffold for proteins involved in signaling, including neuronal nitric oxide synthase (nNOS), phosphoinositol triphosphate 2, calmodulin, and growth factor receptorbound protein 2 (grb2; reviewed in [18]). Additional evidence supports the involvement of the DGC in the extracellular signal-regulated kinases (ERK)/mitogen-activated protein kinase (MAPK) signaling cascade [19], epidermal 
Table 1 Compilation of the known DGC components in human/mice, zebrafish, C. elegans, and Drosophila

\begin{tabular}{|c|c|c|c|c|}
\hline \multirow[t]{2}{*}{ DGC member } & \multicolumn{4}{|l|}{ Species } \\
\hline & $\begin{array}{l}\text { Human/mice (www.dmd.nl) } \\
\text { Protein (gene) }\end{array}$ & $\begin{array}{l}\text { Zebrafish [180] } \\
\text { (www.zfin.org) }\end{array}$ & $\begin{array}{l}\text { C. elegans [33] } \\
\text { (www.wormbase.org) }\end{array}$ & $\begin{array}{l}\text { Drosophila [32] } \\
\text { (www.flybase.bio.indiana.edu) }\end{array}$ \\
\hline \multirow[t]{2}{*}{ Dystrophin } & $\begin{array}{l}\text { Long isoforms: Dp427 } \\
(\mathrm{M}, \mathrm{B}, \mathrm{P})\end{array}$ & $\begin{array}{l}\text { Long isoform: a } 400-\mathrm{kD} \\
\text { dystrophin ortholog }\end{array}$ & $\begin{array}{l}\text { Dystrophin-like } \\
\text { protein }(d y s-1)\end{array}$ & Long isoforms: DLP1-3 \\
\hline & $\begin{array}{l}\text { Short isoforms: Dp260, } \\
\text { Dp140, Dp116, Dp71 (DMD) }\end{array}$ & $\begin{array}{l}\text { Short isoform: Dp71 } \\
\text { (dmd) }\end{array}$ & & $\begin{array}{l}\text { Short isoforms: Dp205, } \\
\text { Dp186, Dp117 (Dys) }\end{array}$ \\
\hline Utrophin & a-, b-, g-Utrophin (utrn) & Utrophin (utrn) [181] & & \\
\hline DRP2 & $\begin{array}{l}\text { Dystrophin-related protein } \\
\text { (DRP2) }\end{array}$ & DRP2 [181] & - & - \\
\hline \multirow[t]{2}{*}{ Dystrobrevin } & $\begin{array}{l}\alpha \text {-Dystrobrevin (DTNA) } \\
\beta \text {-Dystrobrevin (DTNB) }\end{array}$ & $\begin{array}{l}\alpha \text {-Dystrobrevin (dtna) } \\
\beta \text {-Dystrobrevin (dtnb) }\end{array}$ & Dystrobrevin $(d y b-1)$ & Dystrobrevin-like $(D y b)$ \\
\hline & & $\gamma$-Dystrobrevin (dtng) [181] & & \\
\hline Dystroglycan & $\alpha / \beta$-Dystroglycan (DAG1) & $\alpha / \beta$-Dystroglycan (dag1) & Dystroglycan (dgn-1) & Dystroglycan $(D g)$ \\
\hline Sarcoglycan & $\begin{array}{l}\alpha-, \varepsilon-, \beta-, \gamma-, \delta- \\
\quad \zeta \text {-Sarcoglycan (SCGA-Z) }\end{array}$ & $\begin{array}{r}\alpha-, \beta-, \delta-\varepsilon-, \gamma- \\
\zeta-\text { Sarcoglycan }\end{array}$ & $\begin{array}{l}\alpha-, \beta-, \delta / \gamma- \\
\text { Sarcoglycan } \\
(\alpha-, \beta-, \delta / \gamma-\operatorname{sgn})\end{array}$ & $\begin{array}{l}\text { Sarcoglycan- } \alpha, \text { Sarcoglycan- } \beta \text {, } \\
\text { Sarcoglycan- } \delta(\operatorname{Scg} \alpha, S \operatorname{cg} \beta \text {, } \\
S \operatorname{Scg} \delta)\end{array}$ \\
\hline Sarcospan & $\begin{array}{l}\text { Sarcospan (SSPN), } \\
\text { (microspan in mice) }\end{array}$ & Not determined & - & - \\
\hline Syntrophin & $\begin{array}{l}\alpha-, \beta 1-, \beta 2 \text {-Syntrophin } \\
\gamma 1-, \gamma 2 \text {-Syntrophin }\end{array}$ & Not determined & $\begin{array}{l}\beta 1 \text {-Syntrophin }(\text { stn- } 1) \\
\gamma \text {-Syntrophin }\end{array}$ & $\begin{array}{l}\text { Syntrophin-like } 1 \text { and } \\
\text { Syntrophin-like } 2 \text { (Syn-1, Syn-2) }\end{array}$ \\
\hline
\end{tabular}

growth factor receptor-mediated signaling [20], and insulin signaling [21]. Moreover, it has been shown that the DGC is required for neurotransmitter receptor and ion channel clustering and in maintaining calcium $\left(\mathrm{Ca}^{2+}\right)$ homeostasis $[22,23]$.

Since the 1990s, the role of the DGC in brain function has also become the topic of extensive clinical and basic research; however, the mechanisms of action of the different dystrophin isoforms in brain are still largely unknown [5]. Interestingly, a patient was recently described carrying a mutation in the carboxy-terminal region of the $D M D$ gene, who suffered from a mental disorder but showed no signs of muscle weakness [24]. This finding raises the possibility that there may be more patients with cognitive impairments caused by alterations in dystrophin expression or function and demonstrates the important role for dystrophin and its associated proteins in the brain (reviewed by [25]). Moreover, mutations in the gene encoding an enzyme that glycosylates $\alpha$-dystroglycan, protein $O$-mannosyltransferase (POMT) 1, have been associated with a range of muscular dystrophies that are often accompanied by severe mental retardation and ocular abnormalities [26-28]. In recent years, novel gene therapy strategies, such as antisense oligonucleotide-mediated exon-skipping, have been directed toward restoring dystrophin expression in muscle fibers of DMD patients [29]. Promising results have been obtained in a phase I clinical trial [30]. While the application of such approaches in the brain will likely be more challenging, these reports validate the need for preclinical studies to establish the agents and means of delivery required for treatment of DMDassociated nervous system deficits.

Mammalian DMD models, such as the $m d x$ mouse, which lacks the three full-length dystrophin Dp427 isoforms, have been studied most extensively. However, it is now becoming clear that invertebrates such as $C$. elegans and Drosophila can also serve as models to study the fundamental and likely conserved functions of the DGC [31-33]. The reduced functional redundancy of the DGC members [31], the genetic tools available, and the ease of transgenic manipulation render these invertebrate animal models useful. Both the worm and the fly have only a single dystrophin/utrophin ortholog, and their functions may therefore reflect roles played by both dystrophin and utrophin in mammals. Drosophila exhibits muscle degeneration and a reduced lifespan when the expression of certain DGC members are reduced or absent [21, 34-37]. C. elegans lacking DGC components also display severe dystrophy of the musculature, but only in a genetically sensitized background where muscle differentiation is impaired [38]. These findings illustrate the relevance of these models for DMD.

This review focuses on recent insights into the specific roles of the DGC at the synapse gained from studies using mouse and invertebrate animal models. First, we summarize what is known about the function of the DGC at the neuromuscular synapse with emphasis on results obtained from mouse, C. elegans and Drosophila. We then describe the roles of DGC members in central synapses in the brain and the retina and how disruption of the complex may 


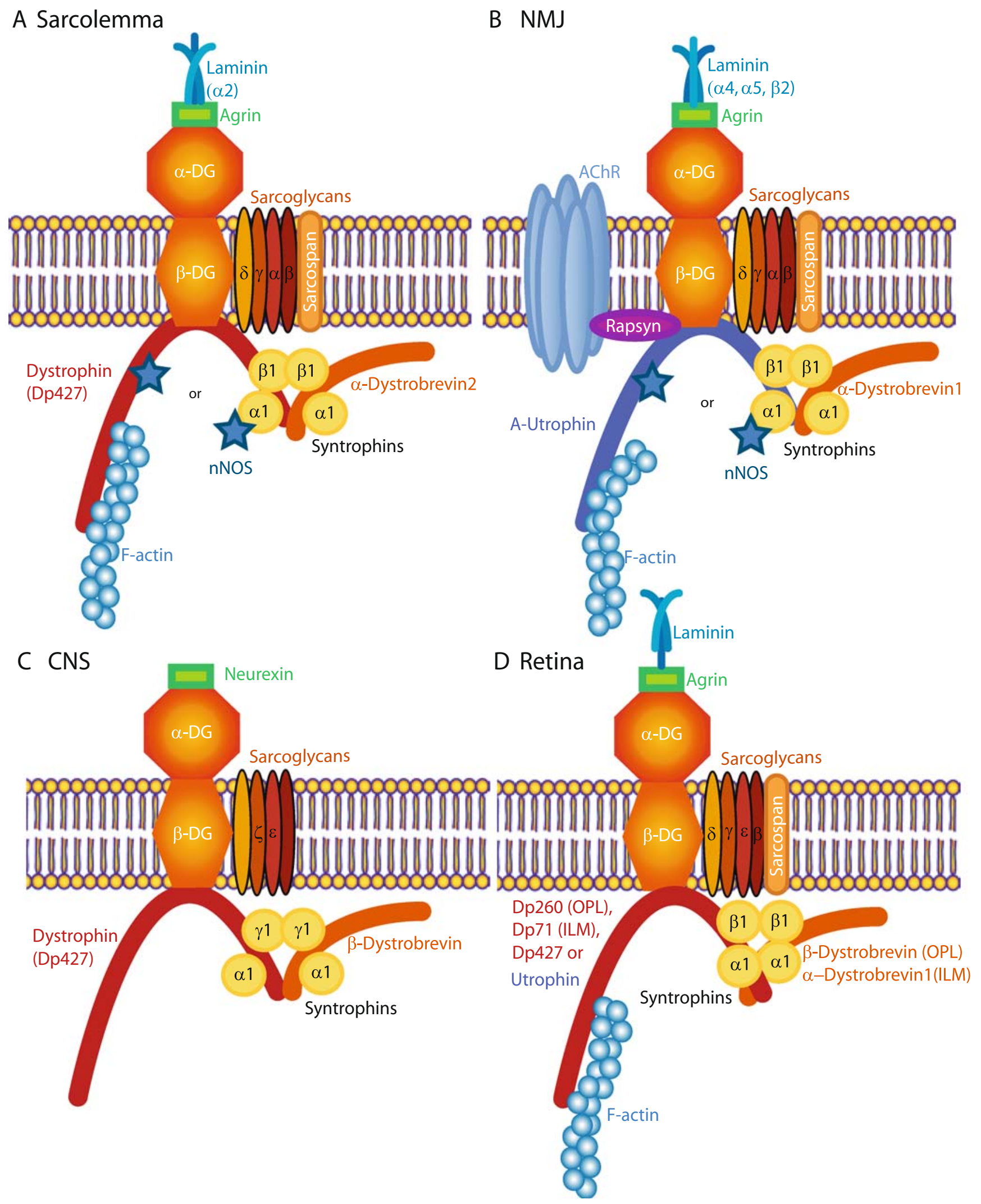


Fig. 1 Differential DGC complex composition at mammalian muscle, NMJ, CNS, and retina. The compositions of the different DGC/UGC complexes that have been reported $[1,7,10,14-16,25,32,39,182]$ to be present in vertebrate muscle (a), at the $\mathrm{NMJ}(\mathbf{b})$, in brain (c), and at the retina (d) are shown. a In skeletal muscle, the N-terminal actinbinding domain and specific spectrin repeats in the central rod of dystrophin bind to costameric F-actin. The cysteine-rich region and the $\mathrm{C}$ terminus of dystrophin establish the link with the DGC through binding to $\beta$-dystroglycan [183] and $\alpha$-dystrobrevin 2 , respectively $[184,185]$. $\beta$-Dystroglycan is linked to the extracellular $\alpha$ dystroglycan, which, depending on the tissue, links laminin $\alpha 2$ along the sarcolemma. In addition, $\beta$-dystroglycan associates with $\delta$ sarcoglycan by which the sarcoglycan-sarcospan complex is stabilized at the sarcolemma [186]. The DGC can bind four syntrophins ( $\alpha 1$ and/ or $\beta 1)$, which in turn recruit sodium channels and signaling molecules, such as nNOS, via their PDZ domains. nNOS can also associate with dystrophin directly via its spectrin-like repeats [72]. b At the NMJ, a similar complex, the UGC, is formed, in which dystrophin can be replaced by A-utrophin and $\alpha$-dystrobrevin 1 replaces $\alpha$-dystrobrevin2 [185, 187]. After postnatal day 7, dystrophin can be detected at the rat NMJ, and therefore, a DGC can also be formed. These proteins bind $\alpha$-syntrophin, which is present at crests and troughs of the junctional folds. $\beta 2$-Syntrophin is mainly localized to the troughs. $\alpha$-Dystroglycan not only binds the laminins $\beta 2, \alpha 4$, and $\alpha 5$ but also the proteoglycans agrin and perlecan. Perlecan is necessary for synaptic localization of acetylcholine esterase, which is involved in termination of cholinergic neurotransmission [188]. The synaptic localization of $\beta$-dystroglycan is dependent on the presence of rapsyn [189, 190], which is important for stabilization of AChR clusters and linkage of these clusters to the UGC at the crests of the junctional folds (reviewed in [51]). $\beta$-Dystroglycan binds to utrophin. c In the brain, the DGC consists of at least four main components, dystrophin or utrophin, dystroglycan, dystrobrevin, and syntrophin, with variations in the isoforms present depending on the cell type. The composition of the sarcoglycan-sarcospan complex is not known for this tissue, but $\delta$ - and $\varepsilon$-sarcoglycan are detected in brain samples. The neuronal DGC consists of a full-length dystrophin isoform (Dp427) bound to $\beta$-dystrobrevin and dystroglycan, which in turn associates with presynaptic neurexin- $\alpha$. The complex also contains $\alpha 1$ - and $\gamma 1$ syntrophin. d In the retina (reviewed in [155]), different dystrophin isoforms are expressed; Dp427, Dp260, Dp140, and Dp 71. Dp260 is highly specific in the photoreceptor terminals of retina [119]. Utrophin is present in the end-feet fraction of Müller glial cells [166]. Dp71 and/or utrophin and $\alpha$-dystroglycan from Müller cells bind actin and laminin, respectively [191]. The sarcoglycan complex which is composed of $\delta$-, $\gamma$ - [191], $\beta$-, and $\varepsilon$-sarcoglycan, and sarcospan $[182]$ is bound to $\beta$-dystroglycan and dystrobrevin. $\beta$-Dystrobrevin is expressed at the outer plexiform layer $(O P L)$ of the retina, while $\alpha$ dystrobrevin 1 is located at the inner limiting membrane (ILM) [134]. Syntrophins, $\alpha 1$ and $\beta 1$, interact with the carboxy-terminus of dystrophin [192]

cause cognitive impairment. Our focus is on the possible signaling pathways interacting with the DGC that may be important for the development or maintenance of peripheral and central synapses.

\section{Roles of the DGC at the Neuromuscular Junction}

In this section the involvement of the DGC at the mammalian neuromuscular junction (NMJ) is discussed in receptor clustering, synaptic transmission, and its participation in a number of important signaling cascades acting at the NMJ, such as the agrin/muscle-specific kinase (MuSK)/rapsin, nNOS, and $\mathrm{Ca}^{2+} /$ calmodulin-dependent protein kinase II (CAMKII)-mediated signaling pathways. In the following Sections, insights obtained in DGC NMJ function using the C. elegans and Drosophila invertebrate model systems which reveal novel roles for dystrophin in neurotransmitter clearance and in the regulation of neurotransmitter release, respectively, are reviewed.

The Involvement of the DGC in AChR Clustering, Synaptic Transmission, and Signaling at the Mammalian NMJ

\section{AChR Density, Junctional Folds, and Transmission Are Reduced at DGC-Deficient NMJS}

The six families of proteins encompassing the DGC can be divided into three subcomplexes: (1) a cytoplasmic complex comprised of dystrophin (or utrophin), dystrobrevin and syntrophin, (2) the transmembrane dystroglycan complex, and (3) the sarcoglycan-sarcospan complex (reviewed in $[1,18,25,39,40])$. Dystrophin is expressed at the sarcolemma of mammalian skeletal muscle and is also found to accumulate at the troughs of the postsynaptic membrane where it colocalizes with voltage-gated sodium channels [41]. Dystrophin is only consistently detected at the mammalian NMJ after postnatal day 7 [42]. Utrophin, however, accumulates at the postsynaptic side of the neuromuscular junction during early postnatal development as part of a protein complex, the utrophin glycoprotein complex (UGC; Fig. 1b), which includes the syntrophins, dystrobrevins, sarcoglycans, sarcospan, and dystroglycan [43]. Dystroglycan interacts with the more general structural and signaling components of the NMJ, including agrin, laminin, and rapsyn and also associates with clusters of acetylcholine receptors (AChRs) at the crests of the junctional folds [41, 42]. In addition, the adaptor protein ankyrin $\mathrm{B}$ is required for localizing the DGC at the mammalian postnatal NMJ [44].

Much has been learned about the mechanisms that underlie the development and function of the vertebrate NMJ (reviewed in [45-47]). A synapse is formed with a highly specialized presynaptic membrane, the active zone, opposing a postsynaptic density enriched in AChRs (in vertebrates) in the crests of the junctional folds and voltage-gated sodium channels in the troughs. Several signaling pathways involved in organizing the initial stages of NMJ formation have been, at least in part, elucidated. One such pathway includes agrin, a heparin sulfate proteoglycan that is released from the motor neuron to activate the postsynaptic tyrosine kinase receptor, MuSK. Engagement of MuSK leads to a second messenger cascade resulting in the clustering of the AChRs, the major 
Table 2 Compilation of the known expression domains of DGC components of human/mice and Drosophila

\begin{tabular}{|c|c|c|c|c|}
\hline \multirow[t]{2}{*}{ DGC member } & \multicolumn{4}{|l|}{ Species } \\
\hline & Human/mice & Expression domain & Drosophila & $\begin{array}{l}\text { Expression } \\
\text { domain (embryo) }\end{array}$ \\
\hline \multirow[t]{8}{*}{ Dystrophin } & Dp427 & $\begin{array}{l}\text { Muscle }(\mathrm{M}) \text {, brain }(\mathrm{B}), \text { Purkinje } \\
\text { cells }(\mathrm{P}) \text {, retina }\end{array}$ & DLP1 & Visceral mesoderm \\
\hline & Dp260 & Retina & DLP2 & $\begin{array}{l}\text { Visceral mesoderm, } \\
\text { musculature, } \\
\text { mesectoderm }\end{array}$ \\
\hline & Dp140 & $\begin{array}{l}\text { Fetal tissues, brain glia, CNS, } \\
\text { retina, kidney }\end{array}$ & DLP3 & Adult \\
\hline & Dp116 & Schwann cells (brain and spinal cord) & Dp205 & $\begin{array}{l}\text { Pericardial cells, VNC, } \\
\text { visceral mesoderm }\end{array}$ \\
\hline & Dp71 & $\begin{array}{l}\text { Ubiquitous, but most prevalent in brain } \\
\text { (microvascular glial and gyrus } \\
\text { dentatus cells), retina, perivascular } \\
\text { astrocytes, liver }\end{array}$ & Dp186 & CNS, midgut \\
\hline & a-Utrophin & $\begin{array}{l}\text { NMJ, fetal muscle, muscle, pia mater, } \\
\text { choroid plexus, astrocytes, renal } \\
\text { glomerulus } \\
\text { Utrophin in retina }\end{array}$ & Dp117 & Musculature, VNC \\
\hline & $\begin{array}{l}\text { b-Utrophin } \\
\text { g-Utrophin } \\
\text { (homolog of Dp116) }\end{array}$ & $\begin{array}{l}\text { Vascular endothelial cells } \\
\text { Sensory ganglia, brain }\end{array}$ & - & - \\
\hline & DRP2 & CNS (brain), Schwann cells & & \\
\hline \multirow[t]{2}{*}{ Dystrobrevin } & $\alpha$-Dystrobrevin & $\begin{array}{l}\text { Skeletal and cardiac muscle, NMJ, } \\
\text { brain, retina, heart, lung }\end{array}$ & Dystrobrevin-like & $\begin{array}{l}\text { Musculature, VNC, } \\
\text { brain, midgut }\end{array}$ \\
\hline & $\beta$-Dystrobrevin & Retina & & \\
\hline Dystroglycan & $\alpha / \beta$-Dystroglycan & Most tissues & Dystroglycan & Musculature, brain, VNC \\
\hline \multirow[t]{3}{*}{ Sarcoglycan } & $\begin{array}{c}\alpha-, \beta-, \gamma-, \text { and } \\
\delta-\text { Sarcoglycan }\end{array}$ & $\begin{array}{l}\text { Skeletal and cardiac muscle } \\
\beta-, \gamma-, \delta \text {-Sarcoglycan in mouse retina }\end{array}$ & $\begin{array}{l}\text { Sarcoglycan- } \alpha, \text { Sarcoglycan- } \beta, \\
\text { Sarcoglycan }-\delta\end{array}$ & CNS, gut, musculature \\
\hline & $\varepsilon$-Sarcoglycan & $\begin{array}{l}\text { Smooth, skeletal and cardiac muscle, } \\
\text { lungs, liver, kidney, brain, Schwann } \\
\text { cells, retina }\end{array}$ & & \\
\hline & $\zeta$-Sarcoglycan & $\begin{array}{l}\text { Brain, skeletal muscle, kidney, } \\
\text { spleen, pancreas }\end{array}$ & & \\
\hline Sarcospan & Sarcospan & Skeletal and cardiac muscle, retina & & - \\
\hline \multirow[t]{2}{*}{ Syntrophin } & $\begin{array}{l}\alpha 1-, \beta 1-, \\
\beta 2-\text { Syntrophin }\end{array}$ & $\begin{array}{l}\text { Skeletal and cardiac muscle, NMJ, } \\
\text { brain, retina, lung, kidney, liver, } \\
\text { pancreas, testes }\end{array}$ & Syntrophin-like 1 & Brain, VNC \\
\hline & $\begin{array}{l}\gamma 1 \text {-Syntrophin } \\
\gamma 2 \text {-Syntrophin }\end{array}$ & Brain, general expression & Syntrophin-like 2 & Mesoderm \\
\hline
\end{tabular}

The data reviewed in this table are taken from $[1,7,10,14-16,25,32,39,182]$

neurotransmitter receptors present at the NMJ. Recently, it was reported that postsynaptic Lrp4 and MuSK act as coreceptors of agrin [48, 49]. Furthermore, Tid1 was identified as a downstream effector of agrin/Lrp4/MuSKinduced AChRs clustering and maintenance, possibly by modulating the organization of the subsynaptic cytoskeleton [50]. The pre- and postsynaptic specializations required for establishment and maintenance of NMJ synapse function are spatially aligned, at least in part, by these interactions.

Rapsyn, an effector protein of MuSK signaling, is also required for AChR clustering. Rapsyn physically links the
AChRs to the UGC, and this interaction seems to be required for $\mathrm{AChR}$ stabilization and maturation of the NMJ (reviewed in [51]). Specifically, when agrin binds to the extracellular region of dystroglycan, it localizes to the NMJ, where it participates with other proteins to cluster the AChR via its intracellular association with rapsyn. While the UGC complex as a whole seems to be required for stabilizing $\mathrm{AChR}$ clusters, rather than being responsible for their initial formation, several components of the UGC, i.e., $\alpha$-dystrobrevin and $\alpha$-syntrophin, are also involved in other signaling events at the NMJ (discussed below). 
A clear indication for an involvement of the UGC in NMJ function came from the observation that knockout mice of dystroglycan, utrophin, $\alpha 1$-syntrophin, or $\alpha$ dystrobrevin display reduced AChR densities at the NMJ [52-56]. These mice also have a reduction in the number of the junctional folds, a morphological defect that might possibly underlie the altered receptor density. The reduction of postsynaptic folds and reduced AChR density is further exacerbated in the double knockout $m d x$; utrn mouse which lacks both utrophin and dystrophin, indicating that dystrophin also plays an important role at the NMJ $[40,57,58]$. Most of these studies were done in mice older than 7 days of age at which stage both dystrophin and utrophin can be detected at the NMJ. Mice deficient in $\alpha$-dystrobrevin show a $70 \%$ reduction in $\mathrm{AChR}$ density, and the remaining receptors are irregularly distributed in aggregates as the distinction between crests and troughs of junctional folds becomes less apparent [59, 60]. Importantly, the initial formation of the NMJs is normal in these mice, but their postnatal maturation is compromised, resulting in the described abnormalities.

Few electrophysiological studies of the DGC/UGCdeficient NMJs have been reported. However, utrn knockout mice exhibit decreased miniature endplate current amplitudes [54], consistent with the reduction in postsynaptic acetylcholine (ACh)-dependent neurotransmitter receptor clusters observed. Interestingly, miniature endplate potentials were also found to be decreased in $m d x$ mice, while these mice display only subtle changes in junctional fold morphology and AChR density [61, 62]. The structural roles of the UGC and DGC in stabilizing NMJ receptor clusters and junctional folds may therefore be independent of their roles in regulating synaptic transmission.

\section{DGC Participation in Signal Transduction Pathways at the Mammalian NMJ}

While the role of the DGC in stabilizing the sarcolemma during repeated cycles of contraction and relaxation is well studied, much less is known about the involvement of the complex as a scaffold for signaling pathways. $\alpha$ Dystrobrevin knockout mice were found to exhibit muscle degeneration in the absence of apparent structural deficits of the sarcolemma [59], suggesting that dystrobrevin may play roles in signaling. Since these mice also show a displacement of nNOS from the membrane, it was hypothesized that impaired nitric oxide (NO) signaling likely contributed to the observed dystrophy [59].

A second clear indication for possible roles of the DGC in signaling was suggested by the observed physical association of the DGC with numerous signaling molecules such as calmodulin, CaMKII, protein kinase A (PKA), phosphoinositide 3-kinases (PI3K), grb2, son of sevenless, and Ras in addition to nNOS. Thirdly, since several DGC pathway members contain potential phosphorylation sites for serine/threonine or tyrosine kinases, DGC function and activation might be regulated by phosphorylation. Indeed, dystrophin is a target of CaMKII-, MAPK-, p34-cde2 kinase-, and casein kinase-dependent phosphorylation in vivo (reviewed in [18]). In cell culture, phosphorylation of dystrophin has been shown to alter its affinity for actin and syntrophin [18].

Direct evidence for a functional role of tyrosine phosphorylation of DGC proteins has only been established for dystrobrevin. $\alpha$-Dystrobrevin mutated at a presumptive tyrosine phosphorylation site failed to fully rescue the NMJ defects in the dystrobrevin knockout mouse [63]. Dystrobrevin is also a target of the serine/threonine kinase PKA [64], a protein implicated in synaptic plasticity, learning, and memory acquisition [65]. Thus, phosphorylation of dystrobrevin at several distinct sites likely modulates its activity during synaptic remodeling.

The DGC actively participates in signaling pathways that are associated with cell survival, cellular defense, and cell growth in a variety of tissues mediated by not only the aforementioned molecules calmodulin, PI3K, and nNOS but also by MAPK, protein kinase B (akt), and the insulin receptor pathway (reviewed in [18]). Here, two examples of pathways relevant for DGC function in the nervous system will be discussed, i.e., DGC participation in nNOS signaling and in $\mathrm{Ca}^{2+}$-mediated homeostasis.

$n N O S$ NOS, which generates NO, plays roles in a number of cellular signaling pathways which, among others, include those involved in apoptosis, in the protection against ischemia, and in regulating vascular tone [66]. While these more general cellular functions are relevant for NOS involvement in the progression of DMD [67], there is also evidence for a more specialized role of NOS in modulating UGC function at the NMJ. NO also acts as both an antero- and retrograde modulator of synaptic transmission at central synapses [68]. While the role of NO in the cerebellum and hippocampus has been studied in great detail, little is known about its possible interactions with the DGC at these synapses.

Indications that nNOS and the UGC/DGC play interdependent roles at the NMJ are supported by the following observations, (1) nNOS is physically associated with the UGC [69], (2) nNOS levels are substantially reduced and nNOS is dislocated from the postsynaptic membrane of DMD patients and in $m d x$ and $\alpha$-syntrophin mutant mice $[67,70]$ and (3) NMJ abnormalities in the $m d x$ mouse (and to a lesser extent in $\alpha$-syntrophin null mutant mice) can be fully rescued upon expression of a nNOS transgene in muscle [71]. However, no such rescue was observed in the $\alpha$-syntrophin/ $\beta 1$-syntrophin double knockout mouse, indi- 
cating that syntrophins may be responsible for recruiting nNOS to the NMJ [71]. It has been recently established that dystrophin itself can also serve as a scaffold for nNOS sarcolemmal targeting [72].

How do alterations in NO levels result in changes in UGC function? Increased NO levels lead to the activation of guanylate cyclase and elevated production of cyclic guanosine monophosphate (cGMP) [73], which subsequently affects contractile function, glucose metabolism [74], and $\mathrm{Ca}^{2+}$ mobilization in muscle fibers [75]. nNOS also acts as an effector of agrin-induced postsynaptic differentiation at the NMJ (reviewed in [76, 77]). In brief, changes in NO and cGMP levels are sufficient to modulate the activity of a number of protein kinases that in turn modify the interaction of the UGC with actin, thereby affecting postsynaptic differentiation. The rod-like region of the dystrophin and utrophin proteins contain potential protein kinase $\mathrm{G}$ (PKG) phosphorylation sites, while potential protein kinase $\mathrm{C}$ (PKC) phosphorylation sites are located near the actin-binding sites [78]. Depending on which site is phosphorylated, F-actin binding to dystrophin and utrophin is promoted (PKG) or inhibited (PKC). According to one proposed model [77], agrin-induced increases in NO/cGMP stimulate PKG and inhibit PKC, resulting in increased interaction of dystrophin and utrophin with actin which results in stabilization of AChR aggregates at the NMJ. Another target of NO, the Src family kinases, then phosphorylates the $\beta$-subunit of AChRs, which promotes their binding to rapsyn and association with other AChRs [51].

Can muscular degeneration in DMD patients be explained solely by a reduction in nNOS levels? This is unlikely, since NOS knockout mice do not display overt dystrophy [79]. However, since increased NO production results in enhanced utrophin expression [80] and treatment of $m d x$ mice with a nNOS substrate, L-arginine, also increases utrophin levels and its membrane localization [81], clinical manipulation of nNOS levels in the muscle is considered a potential starting point for therapeutic intervention [82].

$\mathrm{Ca}^{2+}$ signaling and homeostasis $\mathrm{Ca}^{2+}$ levels in dystrophic muscle are thought to be increased due to disruption of the sarcolemma and abnormal activation of $\mathrm{Ca}^{2+}$ leak channels [83]. It is not clear whether the changes in intracellular $\mathrm{Ca}^{2+}$ levels and disrupted $\mathrm{Ca}^{2+}$ homeostasis observed in dystrophin-deficient muscle are a cause or a result of the pathogenic processes, such as apoptosis and oxidative stress, that occur in dystrophic muscle [83, 84]. It is generally thought, however, that the elevated $\mathrm{Ca}^{2+}$ levels will eventually elicit $\mathrm{Ca}^{2+}$-dependent proteolysis via the activation of calpains and other $\mathrm{Ca}^{2+}$-dependent proteases. In this section, $\mathrm{Ca}^{2+}$ involvement in apoptosis and necrosis of dystrophic DMD fibers is not further discussed. Instead, potential roles for the DGC in the regulation of $\mathrm{Ca}^{2+}$ homeostasis in muscle and at the NMJ under normal physiological conditions are reviewed.

A first insight into a role of the DGC in $\mathrm{Ca}^{2+}$-mediated signaling came from the findings that two of the DGC proteins, i.e., dystrophin and syntrophin, physically interact with calmodulin [85] (reviewed in [18]) and that calmodulin activity is reduced in dystrophin-deficient muscle fibers [86]. Calmodulin is a $\mathrm{Ca}^{2+}$-binding protein that regulates the activity of many $\mathrm{Ca}^{2+}$-sensitive enzymes and acts as a sensor of $\mathrm{Ca}^{2+}$ levels in the cell. Calmodulin is likely to regulate binding of dystrophin/utrophin to actin [87], while the $\mathrm{Ca}^{2+} /$ calmodulin dependent kinase, CaMKII, actively phosphorylates both dystrophin and syntrophin [88]. Dystrophin's interaction with syntrophin is inhibited upon phosphorylation [88], further indicating the regulatory function that CaMKII exerts on DGC activity. In addition, it has been shown that both CaMKII and dystrophin are required for maintaining appropriate levels of neurotransmitter release at the NMJ in Drosophila [89, 90], although at present it is not clear whether they act in the same or parallel pathways.

The DGC also regulates the activity of several $\mathrm{Ca}^{2+}$ channels. Changes in mechanosensitive $\mathrm{Ca}^{2+}$ channel function in $m d x$ muscle fibers, measured by cell-attached patch-clamp recordings, revealed that the probability of these channels being open was increased, presumably leading to increased $\mathrm{Ca}^{2+}$ influx [91]. Changes in $\mathrm{ACh}$ neurotransmitter receptor aggregation caused by the disorganization of the membrane-associated cytoskeleton have been proposed to account for the disturbed $\mathrm{Ca}^{2+}$ homeostasis and increased $\mathrm{Ca}^{2+}$ leakage into dystrophin-deficient muscle [22]. Evidence supporting this hypothesis include the observations that AChR and voltage-gated L-type $\mathrm{Ca}^{2+}$ channel aggregates display unusual physical interactions in dystrophic muscles, which may result in the abnormal $\mathrm{Ca}^{2+}$ influx observed at these sites [22, 92]. Since channel activity measurements vary significantly between different reports, possibly depending on the tissues used, i.e., cultured myotubes versus muscle fibers, or the type of channels studied, a defined role for the DGC in regulating $\mathrm{Ca}^{2+}$ channel activity is far from clear.

Dystrophin Regulates Cholinergic Transmission at the C. elegans NMJ

The highly conserved C. elegans dystrophin ortholog, dys1, was first identified in 1998 [93]. In contrast to mammals, the worm usually has one ortholog for each of the six DGC gene families [33]. For example, it has a dystrophin gene, but no utrophin, DRP2, or sarcospan genes, single 
dystrobrevin and dystroglycan genes, and three sarcoglycan and two syntrophin orthologs (Table 1). Furthermore, the $C$. elegans dystrophin gene encodes only one protein isoform [94]. The reduced potential for functional redundancy has made $C$. elegans and other genetically tractable invertebrates, such as Drosophila, attractive models to study the individual roles of each DGC member.

dys-1 loss-of-function mutants display a characteristic behavioral phenotype: They are hyperactive, bend their head inappropriately when moving forward, and tend to hypercontract [93]. Muscle degeneration is observed only when the dys-1 mutation is placed into sensitized backgrounds with reduced expression levels of the worm ortholog of the myogenic factor, $\mathrm{MyoD}$, which is required for muscle differentiation, or reduced egl-19 $\mathrm{Ca}^{2+}$ channel function [38, 95]. dys-1 mutants, however, display hypersensitivity to ACh and exhibit reduced ACh-esterase activity, indicating a role for dystrophin in cholinergic synaptic transmission at the worm NMJ $[93,96]$. The loss of other worm DGC members, i.e., dystrobrevin or syntrophin, also gives rise to increased cholinergic activity [97].

A subsequent report revealed that inactivation of snf- 6 , a gene encoding a $\mathrm{ACh}$ transporter in $C$. elegans, results in an almost identical hyperactivity phenotype to that seen in dys-1 mutants [98]. Moreover, snf-6 was found to bind to stn-1, the $\beta 1$-syntrophin ortholog expressed in the muscle, and snf- 6 expression is lost from the NMJ of both $d y s-1$ and stn-1 mutants [98]. As observed for $d y s-1$, the snf-6 mutation in combination with a mutation of MyoD results in muscle degeneration. Thus, inefficient clearing of $\mathrm{ACh}$ from the synaptic cleft, due to both a reduction of esterase activity and the loss of the ACh transporter at the DGC mutant NMJ, likely accounts for the behavioral phenotypes observed. Furthermore, it may also contribute to the muscle degeneration observed in DGC sensitized mutant backgrounds. Whether altered cholinergic transmission underlies the dystrophic phenotype in DMD patients remains to be investigated, although increased sensitivity to $\mathrm{ACh}$ has been reported for human cultured myotubes derived from DMD patients [99].

Dystrophin Regulates Glutamatergic Transmission at the Drosophila NMJ

\section{Drosophila Dystrophin Is Required to Maintain Muscle Integrity}

Genomic analyses and expression studies indicate that the Drosophila dystrophin gene encodes three full-length (DLP1-3) and three short dystrophin isoforms (Dp186, Dp205, and Dp117) [32, 94, 100, 101]. DLP2, which is expressed in the musculature throughout development, is most closely related to the mammalian Dp427 isoform.
Similarly to $C$. elegans $d y s-1$ mutants, but unlike mutations in the human Dp427 isoform, Drosophila Dys ${ }^{D L P 2}$ E6 mutants do not display obvious muscle degeneration. However, electrophysiological analyses revealed that neurotransmitter release is increased at the larval NMJ in these mutants [90].

The short Drosophila dystrophin isoform Dp117 is also expressed in the musculature [37]. Interestingly, muscle degeneration was observed in larvae, when all dystrophin isoform expression levels, or Dp117 specifically, were reduced in muscle by transgenic RNA interference [37]. In adult flies, progressive muscle degeneration and impaired climbing ability were observed when dystrophin or dystroglycan expression was reduced [21]. The dystrophin isoform-specific mutant studies suggest that the Drosophila DLP2 protein, which accumulates at the postsynaptic side of the larval NMJ [90], is likely functionally analogous to utrophin at the mammalian $\mathrm{NMJ}$ and required for regulating synaptic transmission. The mechanisms by which Dp117 maintains muscle integrity are not yet clear as this isoform lacks an apparent actin-binding domain. Generation of classical Dp117 mutants and identification of Dp117 protein expression domains should shed further light on its roles.

Further evidence for a role for Drosophila dystrophin in muscle function comes from a study that described an agedependent disruption of the myofibrillar organization of the myocardium in dystrophin mutants lacking the large isoforms, accompanied by reduced cardiac performance and lifespan [36]. Progressive impairment of locomotive ability, disrupted flight muscles, and reduced cardiac function and lifespan were also observed in flies lacking $\delta$-sarcoglycan [34]. Furthermore, in larvae that express reduced levels of dystroglycan or lack POMT1 or POMT2, the protein $O$-mannosyltransferases required for dystroglycan glycosylation in vivo, abnormalities in muscle attachment, muscle contraction, and muscle membrane resistance are reported $[35,102]$. In summary, the requirements for dystrophin, dystroglycan, POMT, and sarcoglycan in maintaining muscle integrity in flies illustrate the usefulness of this invertebrate as a model system for the study of muscular dystrophies.

\section{Does a DGC Exist in Drosophila?}

Although in general the orthologs of the mammalian DGC complex are highly conserved in Drosophila (Table 1), little is known about whether they form DGC-like complexes. No biochemical analyses of dystrophin-containing protein complexes derived from Drosophila tissue preparations or transfected cells have been reported to date. Perhaps the strongest evidence for the existence of a DGC-like protein complex comes from antibody colabeling experiments for multiple members of the DGC at the larval NMJ, the central 
nervous system (CNS), and the muscle. Dystroglycan and laminin colocalize in repeating stripes at sarcomeres [35], suggesting the existence of a T-tubule DGC-like complex, similar to that which is present in vertebrate cardiac muscle. Similarly, dystrophin and dystrobrevin are expressed in overlapping domains at the larval NMJ and in the CNS (S. P., L.G.F., J.N.N, unpublished), while dystrophin and dystroglycan have also been shown to colocalize at the postsynaptic side of the NMJ [103]. Genetic experiments have further indicated that at the NMJ, dystroglycan controls the synaptic localization of dystrophin and laminin $[102,103]$. While direct biochemical data are currently lacking, together these data are consistent with the existence of DGC-like complexes at the Drosophila NMJ.

\section{The Dystrophin Isoform DLP2 Modulates Neurotransmitter Release at the NMJ}

Drosophila larvae that lack the large DLP2 dystrophin isoform exhibit elevated levels of evoked neurotransmitter release at the NMJ [90]. Electrophysiological analyses of DLP2 mutants showed that the resting muscle membrane potential in Dys ${ }^{E 6} D L P 2$ larvae and the depolarization of the muscle caused by spontaneous vesicle release from nerve terminals (miniature amplitude) are unaffected [90]. This suggests that the postsynaptic receptor field is not functionally altered in the mutant. An insight into dystrophin function at the NMJ was revealed by analysis of the effects of evoked stimulation. DLP2 mutants display significantly higher levels of muscle depolarization as compared to control animals indicative of an increased release of presynaptic glutamate. As DLP2 is expressed and required in the muscle [90], this finding indicates that the absence of a postsynaptic dystrophin isoform results in changes in presynaptic function.

Possible explanations for the observed increased neurotransmitter release at the DLP2 mutant NMJ are (a) an increase in probability of release of vesicles or (b) an increase in the available vesicle pool. The vesicle pool was shown to be unaltered in DLP2 mutants, but the probability of release, as deduced from paired-pulse facilitation (PPF; Textbox 2 in "Appendix"), was elevated. Increased numbers of presynaptic active zones with T-bars, specialized structures involved in vesicle docking and release, were also observed thus providing a likely structural correlate to the observed altered synaptic physiology [90]. Postsynaptic dystrophin may act as a scaffold for signaling molecules required for the retrograde control of neurotransmitter release from the presynaptic apparatus. The signaling pathways involved in the dystrophin-dependent increase in synaptic vesicle release remain, however, to be elucidated.

In the last decade, it has become clear that both anterograde, nerve to muscle, and retrograde, muscle to nerve, signals are required to achieve proper synaptic homeostasis (reviewed in [104]). Little is known about the molecular mechanisms required for retrograde control at the NMJ, but one pathway identified as playing roles in this process is the bone morphogenetic protein (BMP) pathway (reviewed in [105]). The secreted BMP pathway member, glass bottom boat, is believed to mediate a signal emanating from the muscle by binding to the presynaptic Wishful Thinking receptor. Interestingly, a genetic interaction was observed with DLP2 and Wishful Thinking at the NMJ, suggesting that dystrophin functions in a BMP-dependent pathway to control homeostatic plasticity [90]. Dystrophin also interacts with BMP signaling pathways in the Drosophila wing where their interplay is required for proper vein formation [106].

What roles do other members of the putative Drosophila DGC play at the synapse? Thus far, only dystroglycan has been examined. Intriguingly, the lack of dystroglycan or the enzyme required for its glycosylation, dPOMT1, both cause a phenotype that is opposite to the DLP2 dystrophin phenotype. Loss of postsynaptic dystroglycan or POMT leads to a decrease in the number of transmitter quanta released from the presynaptic terminal and a concomitant decrease in the efficacy of synaptic transmission $[102,103]$. The probability of release is decreased in these mutants, while the number of release sites is not altered. In addition, while the overall morphology of the NMJ is intact, the ratio of glutamate receptor subunits is altered in dystroglycan and POMT mutants because the levels of the DGluRIIB subunit are reduced.

In Drosophila, the best studied postsynaptic glutamate receptors are GluRIIA and GluRIIB (reviewed in [107]). The subunit composition of the postsynaptic glutamate receptors determines their function and trafficking. Furthermore, the regulation of glutamate receptor subunit ratios may underlie aspects of synaptic homeostasis and plasticity. How these changes would result in alterations in presynaptic release is not known. Nevertheless, changes in postsynaptic subunit composition are also important for the maturation of mouse cholinergic endplates and glutamatergic central synapses [108].

How might the seemingly differential roles of dystrophin and dystroglycan at the Drosophila NMJ be explained? The single mutant analyses have clearly indicated that each of the two proteins function at the neuromuscular synapse, but, surprisingly, in distinct and even opposite ways. Since the phenotypes of dystrophin/dystroglycan double mutant flies have not yet been reported, the epistatic relationship between dystroglycan and dystrophin at the NMJ remains unclear. Dystrophin likely modulates a retrograde signal that limits transmitter release by, at least in part, inhibiting the formation of T-bars. Dystroglycan likely acts via a different mechanism since no alterations in T-bar numbers were observed in the dystroglycan mutant [103]. It is also 
not yet clear whether the change in glutamate receptor composition observed in dystroglycan mutants reflects a direct role of dystroglycan in receptor clustering, as has been shown for the vertebrate dystroglycan protein in AChR clustering [109]. Further studies are required in order to understand these dramatically different roles of dystrophin and dystroglycan at the NMJ.

The increased synaptic efficacy at the Drosophila DLP2deficient NMJ is reminiscent of the elevated levels of cholinergic neurotransmission observed in C. elegans dys-1 mutants. However, as discussed above, the increased depolarization observed in mutant worm muscle is most likely due to the delocalization of the Snf-6 ACh transporter which results in the inappropriate per durance of $\mathrm{ACh}$ in the synaptic cleft. A similar role of a Drosophila dystrophininteracting glutamate transporter at the NMJ cannot be ruled out.

\section{Roles of the DGC at Central Synapses}

We now focus on the roles of dystrophin in the CNS. The first section describes what has been learned about dystrophin function in cognitive studies and behavioral assays which reveal DGC roles in long-term spatial and nonspatial memory consolidation and emotion, respectively. The following section discusses new mechanistic insights into requirement for dystrophin in receptor clustering and synaptic plasticity in the mammalian hippocampus and cerebellum gained, in part, through electrophysiological analyses. The subject of the last section is the recently revealed role of dystrophin in regulating neurotransmitter release at a defined cholinergic central synapse in Drosophila.

Reports that describe dystrophins' involvement in metabolic pathways in the nervous system, such as the altered glucose metabolism in the brains of DMD patients and $m d x$ mice, and those that examine the defects in the establishment of the blood-brain barrier in these mice fall outside the scope of this review. These subjects are reviewed in $[5,25]$.

Roles for Dystrophin in Behavior

\section{DMD Is Associated with Mental Retardation}

Cognitive impairments occur in approximately one third of Duchenne patients, highlighting a role for dystrophin in the nervous system (reviewed in $[5,7,25]$ ). The average IQ of boys diagnosed with DMD is 85 , while $30 \%$ have an IQ less than 70 (reviewed in [5]). These mental deficits appear to be nonprogressive and unrelated to the severity of the muscular dystrophy. Their causes remain unknown. Moreover, morphological abnormalities in the brains of post- mortem DMD patient are highly variable, ranging from no abnormalities [110-112] to slight and severe abnormalities, such as partial cerebral atrophy, neuronal loss and gliosis, and abnormal arborization and dendritic branching of cortical pyramidal neurons [111, 113-115].

There are various neuropsychiatric complications associated with DMD, such as autism, attention deficit hyperactivity disorder, obsessive-compulsive disorder, epilepsy, and febrile convulsion [116]. Mutations in the human fukutin-related protein gene and POMT1/2 genes, which affect the glycosylation of $\alpha$-dystroglycan, also result in syndromes associated with severe mental retardation (Fukuyama congenital muscular dystrophy and WalkerWarburg syndrome), further indicating roles for the DGC in the development of circuitry required for cognition [26]. Lastly, mutations in $\varepsilon$-sarcoglycan are implicated in myoclonus-dystonia syndrome, a disease characterized by dystonia and psychiatric complications, including anxiety and obsessive-compulsive disorder [117].

The brain-specific DGC(s) consists predominantly of four components, dystrophin (or utrophin), dystroglycan, dystrobrevin, and syntrophin (Fig. 1), with variations in the isoforms present, depending on the specific cell type being examined. Some neuronal cell types also express the $\varepsilon$ - and $\zeta$-sarcoglycans, but sarcoglycans are more predominantly expressed in muscle. Dystrophin isoforms are differentially expressed in subsets of neurons and glia: Dp427 is present in the cerebral cortex, the limbic system, including the areas CA1-CA3 of the hippocampus, the basolateral nucleus, and the lateral nucleus of amygdala, and cerebellar Purkinje cells [118]. Dp260 is present in the retina [119], Dp140 in the microvasculature and throughout the brain [120], Dp116 in Schwann cells of the peripheral nervous system [121], while Dp71 is highly abundant in most, if not all, brain areas examined [122]. It is not evident that the lack of one particular dystrophin isoform is solely responsible for the neurological disorders associated with DMD, but mutations in the $3^{\prime}$ end of the gene affecting all isoforms are most frequently linked to lower IQ scores [123]. Furthermore, most DMD patients, who exhibit neurological complications, have a genetic deficiency or duplication distal to exon 44 which most likely alters expression of Dp140, Dp116, and/or Dp71 [116]. Expression of the Dp140 isoform, whose promoter and first exon lie in the large intron between exons 44 and 45 [124], is likely to be affected by these deletions $[125,126]$.

\section{Requirements for the DGC in Memory Acquisition and in Defense and Motor Behavior}

Conflicting reports exist concerning possible roles for dystrophin in learning and memory that have been established using mouse models. The discrepancies are 
likely the result of the use of different behavioral paradigms that test distinct learning tasks of dystrophin-deficient mice [127-129]. In addition, it has become apparent that results obtained from tests employing the $m d x$ mouse (which only lacks full-length dystrophin isoform Dp427) likely differ from those using the $m d x^{3 c v}$ mouse (which lacks all dystrophin isoforms). Together, the results suggest that the full-length isoform is essential for the function of dystrophin in cognition and memory involving hippocampal and forebrain function (reviewed in [25]). The specific roles for the smaller isoforms in cognition are not yet clearly defined. Since $m d x$ mice do not exhibit any significant signs of muscular dystrophy during the first 6 months of postnatal life, possibly due to sufficient regeneration of muscle, behavior of $m d x$ mice can be studied in the absence of extensive muscle degeneration.

Recently, Vaillend and colleagues addressed memory impairment in $m d x$ mice using spatially and nonspatially defined tasks that can be rapidly learned [130]. The use of these behavioral paradigms reduces the possibility that extended training procedures would inadvertently improve memory function and mask memory deficits [131, 132]. The tests were based on (1) object recognition and (2) spatial learning in a water maze. Naturally occurring novelty-seeking behavior was not altered in the $m d x$ mouse confronted with new objects. Both $m d x$ and control mice spent longer times exploring a novel object when it was copresented with a familiar object to which they had been exposed $10 \mathrm{~min}$ prior. However, when the time between exposure and the test was prolonged to $24 \mathrm{~h}$, the $m d x$ group would explore both objects equally, whereas the control group would still prefer a novel object. This observation is consistent with the $m d x$ mice exhibiting long-term recognition memory impairments. Similar results were obtained when mice were trained to find a submerged platform in a water bath. Mice of the control group would still be able to efficiently locate the platform $24 \mathrm{~h}$ after training, as measured by the time spent in the target area, whereas the $m d x$ mice would not show a preference for the area where the platform was located. Thus, apparently, consolidation or expression of long-term memory is impaired in $m d x$ mice [130].

The lack of the large dystrophin isoforms in $m d x$ mice also impacts on emotional behavior and fear memory, which reflects amygdala transmission. $M d x$ mice have an increased defensive freezing response to restraint compared to control mice [133]. This behavior can be partially rescued by oligonucleotide-mediated exon skipping that facilitates expression of a truncated dystrophin in the brain, not in the muscle [133]. These data support the hypothesis that dystrophin is required for wild-type emotional behavior. Behavioral tests have also been performed on double knockout $\alpha$ - and $\beta$-dystrobrevin mice [134]. These mice exhibit abnormal sensorimotor behaviors that reflect cerebellar dysfunction, while the single dystrobrevin knockout mice apparently behave normally.

In the next two sections, electrophysiological studies that examine the roles of the different DGC members at mammalian central synapses are discussed. Furthermore, studies are reviewed that indicate that a number of the DGC members (dystrophin, dystrobrevin, syntrophin, and dystroglycan) are present at the postsynaptic side of mammalian inhibitory GABAergic synapses in the hippocampus and in cerebellar Purkinje cells [135], where they are required for synapse function and plasticity. Lack of expression of dystrophin at these sites might contribute to the behavioral defects observed in $m d x$ mice and the mental retardation displayed by DMD patients.

Dystrophin Function in Receptor Clustering and Synaptic Plasticity of Mammalian Hippocampal and Cerebellar GABAergic Synapses

In the mammalian brain, full-length dystrophin, Dp427 is expressed at the postsynaptic membranes of hippocampal pyramidal neurons, neocortical pyramidal neurons [136], amygdala, and cerebellar Purkinje cells [133] where it colocalizes with inhibitory $\mathrm{GABA}_{\mathrm{A}}$ receptor clusters $[133$, 137]. No gross changes in morphology or increased apoptosis were apparent in the $m d x$ mouse hippocampal CA1 area [138]. However, in other areas of the $m d x$ brain, for example in the spinal trigeminal nucleus, the number of neurons is almost $50 \%$ decreased compared to wild-type mice [139]. Interestingly, in these same mice, $\alpha 1-$ and $\alpha 2$ $\mathrm{GABA}_{\mathrm{A}}$ clusters are significantly reduced in number [133, 137, 140]. Dystrophin colocalizes with other DGC proteins such as dystrobrevin, the syntrophins, and $\beta$-dystroglycan to inhibitory GABAergic synapses [25, 141]. Furthermore, in dystroglycan conditional knockout mice, these synapses no longer contain dystrophin [142]. $\alpha$ - and $\beta$-Dystrobrevin double knockout mice have lost dystrophin, and $m d x$ mice have lost dystrobrevin localization from the cerebellar $\mathrm{GABA}_{\mathrm{A}}$ clusters [134] and exhibit a decrease in the size and numbers of $\alpha 1$ subunit $\mathrm{GABA}_{\mathrm{A}}$ receptor clusters. Together, these data suggest that the DGC proteins are, at least partially, interdependent for their targeting to GABAergic synapses and that the DGC likely stabilizes $\mathrm{GABA}_{\mathrm{A}}$ receptor clusters at these synapses.

There is ample evidence that the DGC members also modulate synapse function at inhibitory GABAergic synapses in the cerebellum [140], the amygdala [133], and the hippocampus (reviewed in [25]). In the $m d x$ cerebellar Purkinje cells, there are significant reductions in both the frequency and amplitude of spontaneous inhibitory postsynaptic currents (mIPSP; Textbox 2 in "Appendix"), consistent with the reduction in the number and size of $\mathrm{GABA}_{\mathrm{A}}$ 
receptor clusters at postsynaptic densities [140]. A reduction in inhibitory input in these cells was also recorded when GABAergic signaling was blocked resulting in a smaller increase in the amplitude of evoked postsynaptic potentials (EPSPs; Textbox 2 in "Appendix"), compared to wild-type controls [143]. Furthermore, decreased long-term depression (LTD; Textbox 2 in "Appendix") was observed in $m d x$ Purkinje cells, which possibly leads to a disruption of cerebellar long-term plasticity [144]. These results may, at least in part, explain some of the behavioral problems and cognitive impairments reported in $m d x$ mice and DMD patients [140].

In the hippocampus, loss of Dp427 in $m d x$ mice does not affect inhibitory postsynaptic currents (IPSCs; Textbox 2 in "Appendix") evoked in the pyramidal cell layer [145]. However, a lack of facilitation was shown by PPF analysis, which suggests that the probability of inhibitory synaptic release is higher in $m d x$ mice compared to control mice at this particular synapse. This effect correlates with an observed increased mIPSC frequency, contrary to what is observed at the cerebellar Purkinje cell synapses discussed above [145]. Several studies by Vaillend and colleagues $[129,130,146]$ demonstrated, again in $m d x$ mice, an increase in neuronal facilitation, a sustained effect leading to enhancement of the maintenance phase of hippocampal long-term potentiation (LTP; Textbox 2 in "Appendix"), as well as an enhancement of short-term potentiation (STP; Textbox 2 in "Appendix") and depression (Textbox 2 in "Appendix"). The enhanced STP and STD were prevented when the $\mathrm{GABA}_{\mathrm{A}}$ receptor antagonist, bicuculline, was applied $[130,146]$. Collectively, these data point toward the dystrophin Dp427 deficiency being associated with a sustained increase in synaptic efficacy and excitability of CA1 hippocampal neurons. Moreover, dystroglycan conditional knockout mice that lack dystroglycan in brain also exhibit deficits in hippocampal LTP [147].

The above-mentioned studies, while showing different electrical responses to dystrophin deficiency in the cerebellum versus the hippocampus, suggest that the alteration of inhibitory synaptic transmission may contribute to memory deficits evident in $m d x$ mice. Similar memory impairments correlating with enhanced synaptic efficacy and LTP have been observed in other mouse models, including a model for Alzheimer's disease, and mice with disrupted genes encoding PSD-95 or a subunit of the ionotropic glutamate receptor [148-151].

Finally, the effects of the loss of the Dp71 isoform on mouse brain function employing electrophysiology and behavioral studies were recently reported [152]. Interestingly, glutamatergic transmission is enhanced and synaptic plasticity reduced in Dp71-deficient CA1 hippocampal neurons. Furthermore, Dp71 knockout mice display reduced exploratory and novelty seeking behavior, mild retention deficits in inhibitory avoidance, and impairments in spatial learning and memory acquisition [152]. Together, the studies described above highlight the different roles that distinct dystrophin isoforms play at central synapses.

Drosophila Dystrophin Modulates Neurotransmitter Release of Cholinergic Central Synapses

Similarly to its mammalian counterpart, the Drosophila dystrophin gene also encodes several short isoforms. One of these, Dp186, is expressed predominantly, if not exclusively, in the CNS [32]. Dp186 has been localized, in particular, to cholinergic synapses between interneurons and motoneurons. Whole-cell voltage clamp recordings from identified motoneurons, in the larval CNS, show that excitatory synaptic currents are significantly increased in the absence of Dp186 compared to those measured in controls [153]. Recordings were also performed in the presence of tetrodotoxin, which blocks evoked transmitter release, allowing measurement of only spontaneous miniature synaptic currents. The amplitudes of these miniature synaptic currents were not altered in the mutants, indicating that the postsynaptic AChR field was not affected by the absence of Dp186. However, although amplitude was normal, the frequency of the miniature synaptic currents was significantly increased in the mutants compared to wild types. Together, these data indicate that lack of Dp186 in the CNS results in an increased probability of presynaptic (ACh) neurotransmitter release. This mutant phenotype could be fully rescued only when a wild-type Dp186 transgene was expressed postsynaptically, but not presynaptically, demonstrating that Dp186 exerts a role consistent with retrograde signaling at interneuronal CNS synapses. Based on similarity of effect, this role likely is similar to that of the large Drosophila DLP2 isoform at the NMJ [90].

\section{Roles of the DGC in the Retina}

One of the earliest described nervous system-related clinical features of DMD patients affects the visual system [154, 155]. While DMD patients have generally normal vision, they do exhibit altered responses to certain light/dark stimuli as measured by electroretinography. Here, recent findings are reviewed that shed light onto DGC function at retinal synapses gained from the use of electrophysiological approaches in animal models.

The DGC Is Required for Correct Electrical Activity and Formation of the Mammalian Retina

Several dystrophin isoforms are differentially expressed in the murine retina $[6,156]$. Based on a number of studies, in which different dystrophin isoforms have been localized to 
specific regions within the retina, it is proposed that each isoform likely contributes a unique function [157]. For example, Dp427 and Dp260 are located in the outer plexiform layer (OPL), where photoreceptors form synapses with horizontal and bipolar cells. Dp71 is detected in the inner limiting membrane, the Müller glia, and the perivascular astrocytes, while Dp140 is also present at perivascular astrocytes $[158,159]$. A special type of synapse at the OPL, called the ribbon synapse, connects axons of photoreceptor cells to bipolar cell dendrites. Visual information is transmitted from the photoreceptor cell to the ganglia cell via the bipolar cells. At the ribbon synapse, Dp260, Dp140, and Dp71, as well as $\beta$-dystroglycan, are expressed presynaptically, in contrast to the postsynaptic expression of DGC members in other parts of the brain and NMJ [51, 160-163].

As indicated above, general eye exams of DMD patients indicate normal visual abilities and no gross abnormalities nor evidence of night blindness. However, DMD patients present with abnormal electroretinograms (ERG; [155]; Textbox 3 in "Appendix"). When measured in a darkadapted (scotopic) retina, the ERG shows a reduced amplitude of the b-wave response in the majority of DMD patients. Further analyses of these ERG waveforms suggest that aberrant dystrophin expression impairs synaptic transmission specifically between the rod and cone photoreceptor cells and their postsynaptic targets, the bipolar ON cells in the OPL [164]. Consistent with these findings, dystrophin expression is observed at these synapses.

Although $m d x$ mice, lacking Dp427, display normal ERG [154], $m d x^{C V 3}$ mice, lacking all dystrophin isoforms, show a decreased b-wave response [165]. Mice that only lack Dp71 [166] have normal ERGs with no significant changes of the b-wave amplitude and kinetics [167]. Based on these results and the above-mentioned expression analyses, the Dp260 isoform is thought to be the isoform likely required for proper b-wave formation and timing. Collaborating evidence for this hypothesis has been obtained from clinical studies of DMD patients. A subset of DMD patients with deletions downstream of exon 30, affecting the splicing and transcription of Dp260, exhibit a red-green color vision defect, while DMD patients, who have dystrophin mutations upstream of exon 30 (solely affecting Dp427) have seemingly normal color vision. Thus, this color vision defect may be caused by a loss of the dystrophin isoform Dp260 [159, 168].

Little is known about the involvement of other DGC members in retinal function. While $\beta$-dystrobrevin colocalizes with dystrophin and $\beta$-dystroglycan at photoreceptor cell termini in the OPL, dystrobrevin null mutant mice display normal ERGs [134]. The localization of dystrophin in the retina is, moreover, not dependent on dystrobrevin expression, unlike their interdependence at inhibitory cellebellar Purkinje synapses. Interestingly, a novel dystro- glycan ligand, called pikachurin, has been recently identified which presynaptically colocalizes with dystrophin and dystroglycan at the photoreceptor ribbon synapse [169]. Pikachurin null mice have improper apposition of bipolar dendritic tips to the photoreceptor ribbon synapse, leading to prolonged retinal synaptic transmission from photoreceptors to bipolars. Pikachurin is therefore important for both the development and function of the ribbon synapse; synapses are formed in Pikachurin null mutants, but the subsequent invagination of the photoreceptor axon surrounding the dendrites of bipolar cells is abnormal, affecting the physiology of visual perception [169]. These animal studies might further our understanding of the exact nature of the defects in vision of DMD patients.

\section{Drosophila DGC Is Required for Axon Guidance of Photoreceptor Neurons}

Studies of the Drosophila optic system recently demonstrated that dystroglycan and dystrophin are required during axon pathfinding of both photoreceptor neurons and their supporting glial cells present in the lamina plexus of the larval brain [21]. Lack of either dystroglycan or dystrophin results in similarly aberrant axon projection patterns: clumping photoreceptor axons at the lamina that are irregularly distributed at the termination zone of the lamina plexus. These abnormalities were also observed when expression of dystroglycan or different isoforms of dystrophin (all isoforms, DLP1-3, or the smaller isoforms only) were reduced by RNA interference either in the photoreceptor axons or the glia, suggesting that both cell types are required for wild-type axon patterning. The observed axon pathfinding phenotypes are reminiscent of phenotypes observed in flies deficient for genes encoding the adaptor protein dock [170] and the insulin receptor (InR) [171]. Genetic interaction studies showed that dystroglycan indeed strongly interacts with dock and InR, whereas dystrophin does not. From these observations, a model was proposed in which dystroglycan may selectively interact with either dystrophin or InR and dock, thereby modulating the cytoskeletal rearrangements in the photoreceptor neurons required for appropriate axonal projections in the retina [21].

\section{Concluding Remarks and Future Perspectives}

Major advances have been made in the clinical assessment of the cognitive and neuropsychiatric impairments of DMD patients and toward the development of animal models to investigate DGC function. However, despite these advances, our understanding of the roles of the complex remains incomplete. A primary challenge ahead for elucidating DGC function in the nervous system is to comprehend how the 
absence of the complex leads to the observed defects in synaptic plasticity, behavioral abnormalities, and visual impairments. At the mechanistic level, it is clear that both at the NMJ and at central synapses, the DGC is required for clustering of major neurotransmitter receptors, such as the AChRs at the NMJ and inhibitory $\mathrm{GABA}_{\mathrm{A}}$ receptor clusters in the hippocampus, the cerebellum, and the amygdala. For a number of these synapses, it has been established that the absence of dystrophin results in aberrant synapse maturation and neurotransmission. Interestingly, DGC/UGC function is apparently not neurotransmitter specific, since the complex is required for appropriate regulation of glutamatergic (Drosophila NMJ and mammalian brain), GABAergic (mammalian brain), and cholinergic (the mammalian and $C$. elegans NMJ and the Drosophila central synapse) transmission. Furthermore, it functions at inhibitory (GABAergic) and excitatory (glutamatergic and cholinergic) synapses.

The definition of the precise synaptic roles of the DGC is complicated by the findings that the effects of DGC deficiency clearly differ depending on the particular synapse studied. In the DGC mutant hippocampus, no gross structural changes in neuronal fate or axon outgrowth were observed. Clear abnormalities in synaptic plasticity and LTP, correlating with alterations in receptor clustering and enhanced synaptic transmission, were, however, evident. In $m d x$ cerebellar Purkinje cells, a reduction in the number of postsynaptically localized $\mathrm{GABA}_{\mathrm{A}}$ clusters has been associated with a decreased amplitude and frequency of spontaneous inhibitory postsynaptic currents and reduction in LTD. These defects may underlie the cognitive impairments these mice exhibit in learning and memory behavioral paradigms. In the coming years, it will hopefully be feasible to directly correlate the mechanistic defects in $m d x$ mice $\mathrm{GABA}_{\mathrm{A}}$ receptor function in the hippocampus and the cerebellum with the observed abnormalities in synaptic plasticity and behavior.

While studies on DGC function in the brain and at the NMJ point toward a mainly postsynaptic role, the complex accumulates at the presynaptic side of the ribbon synapse in the visual system. Here, it is required not only for correct (light-induced) synaptic transmission but also for the structural development of this synapse. In contrast, a role in the stabilization and maturation of the postsynaptically localized neurotransmitter receptor clusters and synaptic folds is evident at the mammalian NMJ, but early morphological development of the NMJ seems to be unaffected in DGC mutants.

Invertebrate organisms, particularly the worm and the fruit fly, have also proven useful for investigating DGC function at the synapse. The fruit fly larval NMJ and central synapses are highly amenable to electrophysiological analysis and specific roles for individual dystrophin isoforms have been identified. Thus, it has been shown that the large dystrophin isoform DLP2 at the glutamatergic NMJ and the smaller Dp186 isoform at cholinergic central synapses, both postsynaptically localized, are required for wild-type levels of presynaptic neurotransmitter release. At the NMJ, at least, this function likely requires BMP signal transduction. Future studies using these invertebrate models, where electrophysiology can be combined with genetic manipulation of single identified cells, should continue to reveal the molecules with which dystrophin interacts at the synapse. Invertebrate animals might also be employed for the large scale screening of potentially therapeutically useful compounds that target DGC function.

Mammalian dystrophin isoforms may also play roles in the regulation of presynaptic neurotransmitter release as has been observed in Drosophila. First, the lack of the Dp71 isoform in the mouse hippocampus leads to alterations in PPF suggesting an increase in presynaptic glutamate release. Secondly, increased mIPSC frequency and reduced PPF of the eIPSCs are observed in the Dp427-deficient hippocampus also indicating increased probability of release. However, the mechanisms underlying these effects on transmitter release remain unknown.

While Drosophila models of dystrophin dysfunction are being increasingly employed, it is currently difficult to precisely determine which of the various fly and mammalian isoforms are functional orthologs. This is for two main reasons: (1) the primary amino acid sequences of the isoform-specific amino-termini differ significantly between Drosophila and mammals (Textbox 1 in "Appendix") and there are no conserved motifs evident and (b) mutants of many of the small isoforms in both species have yet to be examined; thus, their functions are unknown. It remains possible, however, that apparently divergent dystrophin amino-termini play analogous roles in different species. Even if certain aspects of dystrophin function prove, however, to be different between species, studying its roles at various types of synapses in multiple species should help to reveal the biological strategies that have evolved to wire a complex nervous system. This information will aid in the development of novel therapeutic interventions for neurological disorders.

Acknowledgments This work was supported by grants from the "Nederlandse Organisatie voor Wetenschappelijk Onderzoek, N. W. O." (J. N. N. and L. G. F.) and by the Welcome Trust and BBSRC (R. A. B.). We acknowledge Drs. J. T. den Dunnen, J. J. Plomp, A. M. Aartsma-Rus, and J. J. G. M. Verschuuren for providing insightful suggestions on this manuscript.

Open Access This article is distributed under the terms of the Creative Commons Attribution Noncommercial License which permits any noncommercial use, distribution, and reproduction in any medium, provided the original author(s) and source are credited. 


\section{Appendix}

Textbox 1: Dystrophin Isoforms in Mammals, Drosophila, and Worms and Their Mutants

\section{Mammals}

The human/mouse $D M D$ gene has seven promoters driving the expression of mRNAs encoding the isoforms, Dp427 (B), Dp427 (M), Dp427 (P), Dp260, Dp140, Dp116, and Dp71. Three promoters drive expression of the brain- (B), muscle- (M), and Purkinje cell (P)-specific large Dp427 isoforms which differ in their 5' untranslated and first codon exons which are spliced to a common exon 2. All three large isoforms bear an actin-binding domain, four hinge domains interrupted by 24 spectrin-like repeats that form triple-helical coiled-coils (CC) and a C-terminal region that contains domains involved in protein-protein interactions, including a WW domain, a ZZ domain within a cysteine-rich region and a CC domain near the carboxyterminus. The smaller isoforms have the common carboxyterminal region, no apparent actin-binding domains, and a variable number of spectrin-like repeats (Dp260 has 15, Dp140 has 5, Dp116 has 2, and Dp71 has none). Unlike Drosophila and C. elegans, mammals also have an utrophin gene whose encoded protein is highly similar to dystrophin with respect to sequence and domain structure, particularly in the carboxy-terminal domain.

\section{Drosophila}

Drosophila's dystrophin gene contains six identified promoters driving the expression of the following isoforms: DLP1, DLP2, DLP3, Dp186, Dp205, and Dp117. Similar to the large mammalian isoforms, Drosophila DLP1, 2, 3 differ only in their untranslated and first coding exons, but all contain the other conserved protein domain domains described for the mammalian Dp427 isoforms, including 22 spectrin-like repeats [101]. The smaller fly isoforms do not contain conserved actin-binding domains, but Dp186, Dp205, and Dp117 contain unique amino-terminal domains conserved with other Drosophila species and the carboxyterminal domains including WW, ZZ, and CC domains that are present in the mammalian dystrophin protein isoforms. Dp186, Dp205, and Dp117 contain 4, 2 and no spectrin-like repeats, respectively [101].

\section{C. elegans}

C. elegans' dystrophin gene, dys 1 , encodes a single large isoform which bears an actin-binding domain, seven spectrin-like repeats, and the conserved carboxy-terminal domain containing the $\mathrm{WW}, \mathrm{ZZ}$, and $\mathrm{CC}$ domains.
Dystrophin Isoforms Affected in Human DMD Patients and Model Organisms

Approximately two thirds of all DMD patients have large deletions in the dystrophin gene, mostly located at two hot spots that result in the truncation of all protein isoforms and the loss of their common C-terminal domains. The remainder of DMD patients has small deletions or point mutations that introduce stop codons and other mutations that lead to (partial or full) loss of dystrophin protein isoform production or decreased protein stability. Mouse studies discussed in this review employ three different dystrophin-deficient mouse strains, $m d x$ (lacking only the large Dp427 isoforms), $m d x^{3 C v}$ (lacking all isoforms), and Dp71-specific knockout mice. An additional mouse model, $m d x^{52}$, lacking the Dp427, Dp260, and Dp140 isoforms has been generated, but no nervous system phenotypes have been reported. The various mammalian models of DMD have been recently reviewed [172].

The Drosophila mutants described here include mutants lacking only the large DLP2 or CNS-specific Dp186 isoforms or with Dp117 or all dystrophin isoform expression levels reduced by transgenic RNA interference. The $C$. elegans dys 1 mutant lacks the sole dystrophin isoform. Dystrophin isoform expression domains are presented in Table 2.

\section{Textbox 2: Electrophysiological Terminology}

EPSP is a transient depolarization of the postsynaptic membrane caused by the flow of positively charged ions (usually $\mathrm{Na}^{+}$) into the postsynaptic cell as a result of the opening of ligand-gated channels. Depolarization increases the chance of the occurrence of an action potential as the membrane is pushed toward a threshold for the opening of voltage-gated cation channels $\left(\mathrm{Na}^{+}\right.$and/or $\left.\mathrm{Ca}^{2+}\right)$. In contrast, IPSPs (or IPSCs) are mediated by ligand-gated anion channels $\left(\mathrm{Cl}^{-}\right)$and their activation hyperpolarizes the membrane, decreasing the chance of firing action potentials. The spontaneous release of single neurotransmitter quanta from the presynaptic excitatory neuron generates mEPSPs, while the mIPSPs (or mIPSCs) are generated by the release of single quanta at inhibitory synapses [173].

PPF can be described as a short-term form of synaptic plasticity. PPF is the short-lasting $(<1 \mathrm{~s})$ increase in postsynaptic potential evoked by a second impulse. It results in an increase in the probability of transmitter release by residual $\mathrm{Ca}^{2+}$ only when the probability of synaptic vesicle release is low [174].

Another physiological feature in the hippocampus is LTP, first described by Bliss and Lomo [175]. LTP has been defined as a long-lasting increase in synaptic efficacy, meaning that a presynaptic neuron gains an increased 
ability to fire an action potential as a result of brief highfrequency stimulation. LTP can be induced in three major interconnected synaptic circuits of the hippocampus from the dentate gyrus via the CA3 to the CA1 pyramidal neurons. LTP is measured as the percentage increase in the slope of the EPSP relative to the baseline EPSP slope before high-frequency stimulation. LTD is the opposite process, a decrease in neuronal synapse efficacy which can be long lasting, from an hour to days. It is thought to result from changes in postsynaptic receptor density, although changes in presynaptic release may also play a role. LTD is involved in learning and memory processing mediated by the hippocampus and may be important for the clearing of old memory traces [176]. In the cerebellum, LTD has been hypothesized to be important for motor learning. The changes in synaptic strength may be either transient (short term) or persistent (long term). STP refers to synaptic enhancement that can be induced rapidly but maintained only for up to $20 \mathrm{~min}$ [177], while STD results from an activity-dependent reduction in neurotransmitter release [178].

\section{Textbox 3: Electroretinography}

Electroretinography is used to measure the activity of groups of retinal neurons in response to light stimulation, including the photoreceptors (rods and cones) and the ganglion cells. Essentially, the technique records the alterations in the extracellular ion concentration surrounding neurons that changes during action potential firing. If the ERG is performed on a dark-adapted eye (scotopic), it reflects the rod system, and the ERG performed on a lightadapted eye (photopic) shows the response for the cone system. There are two ERG waves: a-waves which are initial negative waves, followed by positive b-waves. The a-wave and b-wave are responsible for a hyperpolarization of rod cells and the summation of the depolarization of ONbipolar cells, respectively. There are two types of bipolar cells, ON (depolarizing)-bipolar cells which activate the ganglion cells in response to an increased brightness, or OFF (hyperpolarizing)-bipolar cells that activate after decreased brightness [179].

\section{References}

1. Blake DJ et al (2002) Function and genetics of dystrophin and dystrophin-related proteins in muscle. Physiol Rev 82:291-329

2. Duchenne G (1868) Recherches sur la paralysie musculaire pseudohypertrophique, ou paralysie myosclerosique. Arch Gen Med 11:5-25

3. Hoffman EP et al (1987) Dystrophin: the protein product of the Duchenne muscular dystrophy locus. Cell 51:919-928
4. Koenig M et al (1987) Complete cloning of the Duchenne muscular dystrophy (DMD) cDNA and preliminary genomic organization of the DMD gene in normal and affected individuals. Cell 50:509-517

5. Anderson JL et al (2002) Brain function in Duchenne muscular dystrophy. Brain 125:4-13

6. Muntoni F et al (2003) Dystrophin and mutations: one gene, several proteins, multiple phenotypes. Lancet Neurol 2:731-740

7. Blake DJ, Kröger S (2000) The neurobiology of Duchenne muscular dystrophy: learning lessons from muscle? Trends Neurosci 23:92-99

8. Love DR et al (1993) Dystrophin and dystrophin-related proteins: a review of protein and RNA studies. Neuromuscul Disord 3:5-21

9. Roberts RG et al (1996) Characterization of DRP2, a novel human dystrophin homologue. Nat Genet 13:223-226

10. Haenggi T, Fritschy JM (2006) Role of dystrophin and utrophin for assembly and function of the dystrophin glycoprotein complex in non-muscle tissue. Cell Mol Life Sci 63:1614-1631

11. Weir AP et al (2002) A- and B-utrophin have different expression patterns and are differentially up-regulated in $\mathrm{mdx}$ muscle. J Biol Chem 277:45285-45290

12. Allikian M, EM EM (2007) Processing and assembly of the dystrophin glycoprotein complex. Traffic 8:177-183

13. Ervasti JM, Campbell KP (1991) Membrane organization of the dystrophin-glycoprotein complex. Cell 66:1121-1131

14. Blake DJ et al (1999) Different dystrophin-like complexes are expressed in neurons and glia. J. Cell Biol. 147:645-658

15. Blank $M$ et al (1999) Dystrophin and beta-dystroglycan in photoreceptor terminals from normal and $\mathrm{mdx} 3 \mathrm{Cv}$ mouse retinae. Eur J NeuroSci 11:2121-2133

16. Blank $M$ et al (1997) Subcellular concentration of betadystroglycan in photoreceptors and glial cells of the chick retina. J Comp Neurol 389:668-678

17. Ervasti JM, Campbell KP (1993) A role for the dystrophinglycoprotein complex as a transmembrane linker between laminin and actin. J Cell Biol 122:809-823

18. Rando TA (2001) The dystrophin-glycoprotein complex, cellular signaling, and the regulation of cell survival in the muscular dystrophies. Muscle Nerve 24:1575-1594

19. Spence HJ et al (2004) Dystroglycan, a scaffold for the ERKMAP kinase cascade. EMBO Rep 5:484-489

20. Hashimoto R, Yamaguchi M (2006) Genetic link between $\beta$ sarcoglycan and the Egfr signaling pathway. Biochem Biophys Res Commun 348:212-221

21. Shcherbata HR et al (2007) Dissecting muscle and neuronal disorders in a Drosophila model of muscular dystrophy. EMBO J 26:481-493

22. Carlson CG (1998) The dystrophinopathies: an alternative to the structural hypothesis. Neurobiol Dis 5:3-15

23. Gillis JM (1996) Membrane abnormalities and Ca homeostasis in muscles of the mdx mouse, an animal model of the Duchenne muscular dystrophy: a review. Acta Physiol Scand 156:397-406

24. Srour $M$ et al (2008) An instructive case of an 8-year-old boy with intellectual disability. Semin Pediatr Neurol 15:154-155

25. Waite A et al (2009) The neurobiology of the dystrophinassociated glycoprotein complex. Ann Med 41:344-359

26. Barresi R, Campbell KP (2006) Dystroglycan: from biosynthesis to pathogenesis of human disease. J Cell Sci 119:199-207

27. Balci B et al (2005) An autosomal recessive limb girdle muscular dystrophy (LGMD2) with mild mental retardation is allelic to Walker-Warburg syndrome (WWS) caused by a mutation in the POMT1 gene. Neuromuscul Disord 15:271-275

28. Beltrán-Valero de Bernabé D et al (2002) Mutations in the Omannosyltransferase gene POMT1 give rise to the severe neuronal migration disorder Walker-Warburg syndrome. Am J Hum Genet 71:1033-1043 
29. van Ommen GJ et al (2008) The therapeutic potential of antisense-mediated exon skipping. Curr Opin Mol Ther 10:140-149

30. van Deutekom JC et al (2007) Local dystrophin restoration with antisense oligonucleotide PRO051. N Engl J Med 357:26772686

31. Greener MJ, Roberts RG (2000) Conservation of components of the dystrophin complex in Drosophila. FEBS Lett 482:13-18

32. Dekkers LC et al (2004) Embryonic expression patterns of the Drosophila dystrophin-associated glycoprotein complex orthologs. Gene Expr Patterns 4:153-159

33. Grisoni K et al (2002) Genetic evidence for a dystrophinglycoprotein complex (DGC) in Caenorhabditis elegans. Gene 294:77-86

34. Allikian MJ et al (2007) Reduced life span with heart and muscle dysfunction in Drosophila sarcoglycan mutants. Hum Mol Genet 16:2933-2943

35. Haines $\mathrm{N}$ et al (2007) Dystroglycan and protein Omannosyltransferases 1 and 2 are required to maintain integrity of Drosophila larval muscles. Mol Biol Cell 18:4721-4730

36. Taghli-Lamallem $O$ et al (2008) Dystrophin deficiency in Drosophila reduces lifespan and causes a dilated cardiomyopathy phenotype. Aging Cell 7:237-249

37. van der Plas MC et al (2007) Drosophila dystrophin is required for integrity of the musculature. Mech Dev 124:617-630

38. Gieseler K et al (2000) Genetic suppression of phenotypes arising from mutations in dystrophin-related genes in Caenorhabditis elegans. Curr Biol 10:1092-1097

39. Ozawa E et al (2005) Molecular and cell biology of the sarcoglycan complex. Muscle Nerve 32:563-576

40. Rafael JA et al (2000) Dystrophin and utrophin influence fiber type composition and post-synaptic membrane structure. Hum Mol Genet 9:1357-1367

41. Wood SJ, Slater CR (1998) Beta-spectrin is colocalized with both voltage-gated sodium channels and ankyrinG at the adult rat neuromuscular junction. J Cell Biol 140:675-684

42. Bewick GS et al (1996) Spatial relationships of utrophin, dystrophin, beta-dystroglycan and beta-spectrin to acetylcholine receptor clusters during postnatal maturation of the rat neuromuscular junction. J Neurocytol 25:367-379

43. Marchand S, Cartaud FS-MJ (2001) Differential targeting of components of the dystrophin complex to the postsynaptic membrane. Eur J NeuroSci 13:221-229

44. Ayalon $G$ et al (2008) An ankyrin-based mechanism for functional organization of dystrophin and dystroglycan. Cell 135:1189-1200

45. Burden SJ (2002) Building the vertebrate neuromuscular synapse. J Neurobiol 53:501-511

46. Sanes JR, Lichtman JW (1999) Development of the vertebrate neuromuscular junction. Ann Rev Neurosci 22:389-442

47. Sanes JR, Lichtman JW (2001) Induction, assembly, maturation and maintenance of a postsynaptic apparatus. Nature Rev Neurosci 2:791-805

48. Kim N et al (2008) Lrp4 is a receptor for Agrin and forms a complex with MuSK. Cell 135:334-342

49. Zhang B et al (2008) LRP4 serves as a coreceptor of agrin. Neuron 60:285-297

50. Linnoila $\mathrm{J}$ et al (2008) A mammalian homolog of Drosophila tumorous imaginal discs, Tid1, mediates agrin signaling at the neuromuscular junction. Neuron 60:625-641

51. Banks GB et al (2003) The postsynaptic submembrane machinery at the neuromuscular junction: requirement for rapsyn and the utrophin/dystrophin-associated complex. J Neurocytol 32:709-726

52. Adams ME et al (2000) Absence of alpha-syntrophin leads to structurally aberrant neuromuscular synapses deficient in utrophin. J Cell Biol 150:1385-1398
53. Akaaboune $\mathrm{M}$ et al (2002) Neurotransmitter receptor dynamics studied in vivo by reversible photo-unbinding of fluorescent ligands. Neuron 34:865-876

54. Deconinck AE et al (1997) Postsynaptic abnormalities at the neuromuscular junctions of utrophin-deficient mice. J Cell Biol 136:883-894

55. Grady RM et al (1997) Subtle neuromuscular defects in utrophin-deficient mice. J Cell Biol 136:871-882

56. Jacobson C et al (2001) The dystroglycan complex is necessary for stabilization of acetylcholine receptor clusters at neuromuscular junctions and formation of the synaptic basement membrane. J Cell Biol 152:435-450

57. Deconinck AE et al (1997) Utrophin-dystrophin-deficient mice as a model for Duchenne muscular dystrophy. Cell 90:717-727

58. Grady RM et al (1997) Skeletal and cardiac myopathies in mice lacking utrophin and dystrophin: a model for Duchenne muscular dystrophy. Cell 90:729-738

59. Grady RM et al (1999) Role for alpha-dystrobrevin in the pathogenesis of dystrophin-dependent muscular dystrophies. Nature Cell Biol 1:215-220

60. Grady RM et al (2000) Maturation and maintenance of the neuromuscular synapse: genetic evidence for roles of the dystrophin-glycoprotein complex. Neuron 25:279-293

61. Carlson CG, Roshek DM (2001) Adult dystrophic (mdx) endplates exhibit reduced quantal size and enhanced quantal variation. Pflugers Arch 442:369-375

62. Nagel A et al (1990) Neuromuscular transmission in the $m d x$ mouse. Muscle Nerve 13:742-749

63. Grady RM et al (2003) Tyrosine-phosphorylated and nonphosphorylated isoforms of alpha-dystrobrevin: roles in skeletal muscle and its neuromuscular and myotendinous junctions. J Cell Biol 160:741-752

64. Ceccarini $M$ et al (2007) Association of dystrobrevin and regulatory subunit of protein kinase A: a new role for dystrobrevin as a scaffold for signaling proteins. J Mol Biol 371:1174-1187

65. Waltereit R, Weller M (2003) Signaling from cAMP/PKA to MAPK and synaptic plasticity. Mol Neurobiol 27:99-106

66. Southan GJ, Szabó C (1996) Selective pharmacological inhibition of distinct nitric oxide synthase isoforms. Biochem Pharmacol 51:383-394

67. Gücüyener K et al (2000) The serum nitric oxide levels in patients with Duchenne muscular dystrophy. Brain Dev 22:181183

68. Feil R, Kleppisch T (2008) NO/cGMP-dependent modulation of synaptic transmission. Handb Exp Pharmacol 184:529-560

69. Chaubourt E et al (2002) Muscular nitric oxide synthase (muNOS) and utrophin. J Physiol-Paris 96:43-52

70. Daniel S, Chao FS (1998) Muscular dystrophy in mdx mice despite lack of neuronal nitric oxide synthase. J Neurochem 71:784-789

71. Shiao T et al (2004) Defects in neuromuscular junction structure in dystrophic muscle are corrected by expression of a NOS transgene in dystrophin-deficient muscles, but not in muscles lacking $\alpha$ and $\beta$-syntrophins. Hum Mol Genet 13:1873-1884

72. Lai $Y$ et al (2009) Dystrophins carrying spectrin-like repeats 16 and 17 anchor nNOS to the sarcolemma and enhance exercise performance in a mouse model of muscular dystrophy. J Clin Invest 119:624-635

73. Bellamy TC et al (2002) On the activation of soluble guanylyl cyclase by nitric oxide. PNAS (USA) 99:507-510

74. Bergandi $L$ et al (2003) Insulin stimulates glucose transport via nitric oxide/cyclic GMP pathway in human vascular smooth muscle cells. Arterioscler Thromb Vasc Biol 23:2215-2221

75. Christensen EN, Mendelsohn ME (2006) Cyclic GMP-dependent protein kinase I\{alpha\} inhibits thrombin receptor-mediated 
calcium mobilization in vascular smooth muscle cells. J Biol Chem 281:8409-8416

76. Blottner D, Luck G (2001) Just in time and place: NOS/NO system assembly in neuromuscular junction formation. Microsc Res Tech 55:171-180

77. Godfrey EW, Schwarte RC (2003) The role of nitric oxide signaling in the formation of the neuromuscular junction. $\mathrm{J}$ Neurocytol 32:591-602

78. Senter L et al (1995) Phosphorylation of dystrophin: effects on actin binding. Biochem Biophys Res Commun 206:57-63

79. Nelson RJ et al (1995) Behavioural abnormalities in male mice lacking neuronal nitric oxide synthase. Nature 378:383-386

80. Chaubourt E et al (2000) The NO way to increase muscular utrophin expression? C R Acad Sci III 323:735-740

81. Chaubourt E et al (1999) Nitric oxide and -arginine cause an accumulation of utrophin at the sarcolemma: a possible compensation for dystrophin loss in Duchenne muscular dystrophy. Neurobiol Dis 6:499-507

82. Voisin V et al (2005) 1-Arginine improves dystrophic phenotype in mdx mice. Neurobiol Dis 20:123-130

83. Alderton JM, Steinhardt RA (2000) Calcium influx through calcium leak channels is responsible for the elevated levels of calcium-dependent proteolysis in dystrophic myotubes. J Biol Chem 275:9452-9460

84. Whitehead NP et al (2006) Muscle damage in $m d x$ (dystrophic) mice: role of calcium and reactive oxygen species. Clin Exp Pharmacol Physiol 33:657-662

85. Madhavan R et al (1992) Calmodulin specifically binds three proteins of the dystrophin-glycoprotein complex. Biochem Biophys Res Commun 185:753-759

86. Niebroj-Dobosz I et al (1989) Elevated calmodulin levels and reduced calmodulin-stimulated calcium-ATPase in Duchenne progressive muscular dystrophy. Neurology 39:1610-1614

87. Winder SJ, Kendrick-Jones J (1995) Calcium/calmodulin-dependent regulation of the $\mathrm{NH} 2$-terminal $\mathrm{F}$-actin binding domain of utrophin. FEBS Lett 357:125-128

88. Calderilla-Barbosa L et al (2006) Phosphorylation of dystrophin Dp71d by $\mathrm{Ca} 2+/$ calmodulin-dependent protein kinase II modulates the Dp71d nuclear localization in PC12 cells. J Neurochem 98:713722

89. Haghighi AP et al (2003) Retrograde control of synaptic transmission by postsynaptic CaMKII at the Drosophila neuromuscular junction. Neuron 39:255-267

90. van der Plas MC et al (2006) Dystrophin is required for appropriate retrograde control of neurotransmitter release at the Drosophila neuromuscular junction. J Neurosci 26:333-344

91. Franco-Obregon A Jr, Lansman JB (1994) Mechanosensitive ion channels in skeletal muscle from normal and dystrophic mice. J Physiol 481(Pt 2):299-309

92. Constantin B et al (2006) New insights in the regulation of calcium transfers by muscle dystrophin-based cytoskeleton: implications in DMD. J Muscle Res Cell Motil 27:375-386

93. Bessou C et al (1998) Mutations in the Caenorhabditis elegans dystrophin-like gene dys-1 lead to hyperactivity and suggest a link with cholinergic transmission. Neurogenetics 2:61-72

94. Roberts RG, Bobrow M (1998) Dystrophins in vertebrates and invertebrates. Hum Mol Genet 7:589-595

95. Gieseler K et al (2001) Molecular, genetic and physiological characterisation of dystrobrevin-like (dyb-1) mutants of Caenorhabditis elegans. J Mol Biol 307:107-117

96. Giugia J et al (1999) Mutations in the dystrophin-like dys-1 gene of Caenorhabditis elegans result in reduced acetylcholinesterase activity. FEBS Lett 463:270-272

97. Gieseler K et al (1999) Dystrobrevin- and dystrophin-like mutants display similar phenotypes in the nematode Caenorhabditis elegans. Neurogenetics 2:87-90
98. Kim H et al (2004) SNF-6 is an acetylcholine transporter interacting with the dystrophin complex in Caenorhabditis elegans. Nature 430:891-896

99. Meola G et al (1991) Growth and differentiation of myogenic clones from adult human muscle cell cultures. Eur J Basic Appl Histochem 35:219-231

100. Neuman S et al (2001) The dystrophin/utrophin homologues in Drosophila and in sea urchin. Gene 263:17-29

101. Neuman S et al (2005) The Drosophila homologue of the dystrophin gene-introns containing promoters are the major contributors to the large size of the gene. FEBS Lett 579:5365-5371

102. Wairkar YP et al (2008) Synaptic defects in a Drosophila model of congenital muscular dystrophy. J Neurosci 28:3781-3789

103. Bogdanik L et al (2008) Muscle dystroglycan organizes the postsynapse and regulates presynaptic neurotransmitter release at the Drosophila neuromuscular junction. PLoS ONE 3:e2084

104. Frank CA et al (2006) Mechanisms underlying the rapid induction and sustained expression of synaptic homeostasis. Neuron 52:663-677

105. Keshishian H, Kim YS (2004) Orchestrating development and function: retrograde BMP signaling in the Drosophila nervous system. Trends Neurosci 27:143-147

106. Christoforou CP et al (2008) The detached locus encodes Drosophila dystrophin, which acts with other components of the dystrophin associated protein complex to influence intercellular signalling in developing wing veins. Dev Biol 313:519-532

107. DiAntonio A (2006) Glutamate receptors at the Drosophila neuromuscular junction. Int Rev Neurobiol 75:165-179

108. Takahashi T (2005) Postsynaptic receptor mechanisms underlying developmental speeding of synaptic transmission. Neurosci Res 53:229-240

109. Jacobson C et al (1998) alpha-Dystroglycan functions in acetylcholine receptor aggregation but is not a coreceptor for agrin-MuSK signaling. J Neurosci 18:6340-6348

110. al-Qudah AA et al (1990) Etiology of intellectual impairment in Duchenne muscular dystrophy. Pediatr Neurol 6:57-59

111. Bresolin N et al (1994) Cognitive impairment in Duchenne muscular dystrophy. Neuromuscul Disord 4:359-369

112. Rae C et al (1998) Brain biochemistry in Duchenne muscular dystrophy: a $1 \mathrm{H}$ magnetic resonance and neuropsychological study. J Neurol Sci 160:148-157

113. Jagadha V, Becker LE (1988) Brain morphology in Duchenne muscular dystrophy: a Golgi study. Pediatr Neurol 4:87-92

114. Septien L et al (1991) Mental development in Duchenne muscular dystrophy. Correlation of data of the brain scanner. Pediatrie 46:817-819

115. Yoshioka M et al (1980) Central nervous system involvement in progressive muscular dystrophy. Arch Dis Child 55:589-594

116. Nakamura A et al (2008) Various central nervous system involvements in dystrophinopathy: clinical and genetic considerations. No To Hattatsu 40:10-14

117. Zimprich A et al (2001) Mutations in the gene encoding $\varepsilon$ sarcoglycan cause myoclonus-dystonia syndrome. Nat Genet 29:66-69

118. Moukhles H, Carbonetto S (2001) Dystroglycan contributes to the formation of multiple dystrophin-like complexes in brain. $\mathrm{J}$ Neurochem 78:824-834

119. D'Souza VN et al (1995) A novel dystrophin isoform is required for normal retinal electrophysiology. Hum Mol Genet 4:837-842

120. Lidov HGW et al (1995) Dp140: a novel 140 kDa CNS transcript from the dystrophin locus. Hum Mol Genet 4:329-335

121. Byers TJ et al (1993) An alternative dystrophin transcript specific to peripheral nerve. Nature Genet 4:77-81

122. Richard CA et al (1995) Cloning and characterization of alternatively spliced isoforms of Dp71. Hum Mol Genet 4:1475-1483 
123. Moizard MP et al (2000) Severe cognitive impairment in DMD: obvious clinical indication for Dp71 isoform point mutation screening. Eur J Hum Genet 8:552-556

124. Lidov HG, Kunkel LM (1997) Dp140: alternatively spliced isoforms in brain and kidney. Genomics 45:132-139

125. Bardoni A et al (1999) Absence of brain Dp140 isoform and cognitive impairment in Becker muscular dystrophy. Lancet 353:897-898

126. Felisari G et al (2000) Loss of Dp140 dystrophin isoform and intellectual impairment in Duchenne dystrophy. Neurology 55:559-564

127. Muntoni F et al (1991) Passive avoidance behaviour deficit in the mdx mouse. Neuromuscul Disord 1:121-123

128. Sesay AK et al (1996) Spatial learning and hippocampal longterm potentiation are not impaired in mdx mice. Neurosci Lett 211:207-210

129. Vaillend C et al (1998) Spatial discrimination learning and CA1 hippocampal synaptic plasticity in $\mathrm{mdx}$ and $\mathrm{mdx} 3 \mathrm{cv}$ mice lacking dystrophin gene products. Neurosci 86:53-66

130. Vaillend $C$ et al (2004) Impaired long-term spatial and recognition memory and enhanced CA1 hippocampal LTP in the dystrophindeficient Dmd(mdx) mouse. Neurobiol Dis 17:10-20

131. Bozon B et al (2003) MAPK, CREB and zif268 are all required for the consolidation of recognition memory. Philos Trans R Soc Lond B Biol Sci 358:805-814

132. Genoux D et al (2002) Protein phosphatase 1 is a molecular constraint on learning and memory. Nature 418:970-975

133. Sekiguchi $M$ et al (2009) A deficit of brain dystrophin impairs specific amygdala GABAergic transmission and enhances defensive behaviour in mice. Brain 132:124-135

134. Grady RM et al (2006) Cerebellar synaptic defects and abnormal motor behavior in mice lacking alpha- and beta-dystrobrevin. $\mathrm{J}$ Neurosci 26:2841-2851

135. Lidov HG (1996) Dystrophin in the nervous system. Brain Pathol 6:63-77

136. Lidov HG et al (1990) Localization of dystrophin to postsynaptic regions of central nervous system cortical neurons. Nature 348:725-728

137. Knuesel I et al (1999) Short communication: altered synaptic clustering of GABAA receptors in mice lacking dystrophin ( $\mathrm{mdx}$ mice). Eur J NeuroSci 11:4457-4462

138. Miranda R et al (2009) Reorganization of inhibitory synapses and increased PSD length of perforated excitatory synapses in hippocampal area CA1 of dystrophin-deficient mdx mice. Cereb Cortex 19:876-888

139. Pinto ML et al (2008) Loss of neuronal projections in the dystrophin-deficient $\mathrm{mdx}$ mouse is not progressive. Brain Res 1224:127-132

140. Kueh SL et al (2008) GABA(A) receptor expression and inhibitory post-synaptic currents in cerebellar Purkinje cells in dystrophin-deficient mdx mice. Clin Exp Pharmacol Physiol 35:207-210

141. Brunig I et al (2002) GABAergic terminals are required for postsynaptic clustering of dystrophin but not of GABA(A) receptors and gephyrin. J Neurosci 22:4805-4813

142. Levi $\mathrm{S}$ et al (2002) Dystroglycan is selectively associated with inhibitory GABAergic synapses but is dispensable for their differentiation. J Neurosci 22:4274-4285

143. Anderson JL et al (2003) Altered inhibitory input to Purkinje cells of dystrophin-deficient mice. Brain Res 982:280-283

144. Anderson JL et al (2004) Long-term depression is reduced in cerebellar Purkinje cells of dystrophin-deficient mdx mice. Brain Res 1019:289-292

145. Graciotti L et al (2008) GABAergic miniature spontaneous activity is increased in the CA1 hippocampal region of dystrophic mdx mice. Neuromuscul Disord 18:220-226
146. Vaillend C, Billard JM (2002) Facilitated CA1 hippocampal synaptic plasticity in dystrophin-deficient mice: role for GABAA receptors? Hippocampus 12:713-717

147. Moore SA et al (2002) Deletion of brain dystroglycan recapitulates aspects of congenital muscular dystrophy. Nature 418:422-425

148. Gerlai R (1998) A new continuous alternation task in T-maze detects hippocampal dysfunction in mice. A strain comparison and lesion study. Behav Brain Res 95:91-101

149. Gerlai R et al (1998) Multiple behavioral anomalies in GluR2 mutant mice exhibiting enhanced LTP. Behav Brain Res 95:37-45

150. Gerlai R et al (1998) Altered spatial learning and memory in mice lacking the mGluR4 subtype of metabotropic glutamate receptor. Behav Neurosci 112:525-532

151. Migaud $\mathrm{M}$ et al (1998) Enhanced long-term potentiation and impaired learning in mice with mutant postsynaptic density-95 protein. Nature 396:433-439

152. Daoud F et al (2009) Role of mental retardation-associated dystrophin-gene product Dp71 in excitatory synapse organization, synaptic plasticity and behavioral functions. PLoS ONE 4(8):e6574

153. Fradkin LG et al (2008) The dystrophin Dp186 isoform regulates neurotransmitter release at a central synapse in Drosophila. J Neurosci 28:5105-5114

154. Cibis GW et al (1993) The effects of dystrophin gene mutations on the ERG in mice and humans. Invest Ophthalmol Vis Sci 34:3646-3652

155. Pillers DA et al (1993) Dystrophin expression in the human retina is required for normal function as defined by electroretinography. Nature Genet 4:82-86

156. Tamura $\mathrm{T}$ et al (1993) Dystrophin isoforms expressed in the mouse retina. J Neurol Sci 115:214-218

157. Howard PL et al (1998) Localization of dystrophin isoform Dp71 to the inner limiting membrane of the retina suggests a unique functional contribution of Dp71 in the retina. Hum Mol Genet $7: 1385-1391$

158. Claudepierre T et al (1999) Differential distribution of dystrophins in rat retina. Invest Opthamol Vis Sci 40:1520-1529

159. Pillers D-AM et al (1999) Duchenne/Becker muscular dystrophy: correlation of phenotype by electroretinography with sites of dystrophin mutations. Hum Genet 105:2-9

160. Jastrow $\mathrm{H}$ et al (2006) Identification of a beta-dystroglycan immunoreactive subcompartment in photoreceptor terminals. Invest Ophthalmol Vis Sci 47:17-24

161. Schmitz F, Drenckhahn D (1997) Dystrophin in the retina. Prog Neurobiol 53:547-560

162. Schmitz F, Drenckhahn D (1997) Localization of dystrophin and beta-dystroglycan in bovine retinal photoreceptor processes extending into the postsynaptic dendritic complex. Histochem Cell Biol 108:249-255

163. Ueda $\mathrm{H}$ et al (1997) Dystrophin in rod spherules; submembranous dense regions facing bipolar cell processes. Histochem Cell Biol 108:243-248

164. Fitzgerald KM et al (1994) Retinal signal transmission in Duchenne muscular dystrophy: evidence for dysfunction in the photoreceptor/depolarizing bipolar cell pathway. J Clin Invest 93:2425-2430

165. Green DG et al (2004) Normal photoresponses and altered bwave responses to $\mathrm{APB}$ in the $\operatorname{mdx}(\mathrm{Cv} 3)$ mouse isolated retina ERG supports role for dystrophin in synaptic transmission. Vis Neurosci 21:739-747

166. Fort PE et al (2008) Kir4.1 and AQP4 associate with Dp71- and utrophin-DAPs complexes in specific and defined microdomains of Muller retinal glial cell membrane. Glia 56:597-610

167. Dalloz C et al (2003) Targeted inactivation of dystrophin gene product Dp71: phenotypic impact in mouse retina. Hum Mol Genet 12:1543-1554 
168. Costa MF et al (2007) Red-green color vision impairment in Duchenne muscular dystrophy. Am J Hum Genet 80:1064-1075

169. Sato $\mathrm{S}$ et al (2008) Pikachurin, a dystroglycan ligand, is essential for photoreceptor ribbon synapse formation. Nat Neurosci 11:923-931

170. Garrity PA et al (1996) Drosophila photoreceptor axon guidance and targeting requires the dreadlocks $\mathrm{SH} 2 / \mathrm{SH} 3$ adapter protein. Cell 85:639-650

171. Song J et al (2003) Axons guided by insulin receptor in Drosophila visual system. Science 300:502-505

172. Willmann R et al (2009) Mammalian animal models for Duchenne muscular dystrophy. Neuromuscul Disord 19:241-249

173. Thomson AM, Deuchars J (1997) Synaptic interactions in neocortical local circuits: dual intracellular recordings in vitro. Cereb Cortex 7:510-522

174. Zucker RS, Regehr WG (2002) Short-term synaptic plasticity. Ann Rev Physiol 64:355-405

175. Bliss TVP, Lomo T (1973) Long-lasting potentiation of synaptic transmission in the dentate area of the anaesthetized rabbit following stimulation of the perforant path. J Physiol 232:331356

176. Bear MF, Abraham WC (1996) Long-term depression in hippocampus. Ann Rev Neurosci 19:437-462

177. Kombian SB et al (2000) Short-term potentiation of miniature excitatory synaptic currents causes excitation of supraoptic neurons. J Neurophysiol 83:2542-2553

178. Wu Y et al (2005) Properties of short-term synaptic depression at larval neuromuscular synapses in wild-type and temperaturesensitive paralytic mutants of Drosophila. J Neurophysiol 93:2396-2405

179. Schiller PH et al (1986) Functions of the ON and OFF channels of the visual system. Nature 322:824-825

180. Guyon JR et al (2003) The dystrophin associated protein complex in zebrafish. Hum Mol Genet 12:601-615
181. Böhm S et al (2008) Dystrobrevin and dystrophin family gene expression in zebrafish. Gene Expr Patterns 8:71-78

182. Fort $P$ et al (2005) The sarcoglycan-sarcospan complex localization in mouse retina is independent from dystrophins. Neurosci Res 53:25-33

183. Ishikawa-Sakurai M et al (2004) ZZ domain is essentially required for the physiological binding of dystrophin and utrophin to $\beta$-dystroglycan. Hum Mol Genet 13:693-702

184. Balasubramanian S et al (1998) Characterization of the tyrosine phosphorylation and distribution of dystrobrevin isoforms. FEBS Lett 432:133-140

185. Peters MF et al (1998) Differential membrane localization and intermolecular associations of alpha-dystrobrevin isoforms in skeletal muscle. J Cell Biol 142:1269-1278

186. Crosbie RH et al (2000) Molecular and genetic characterization of sarcospan: insights into sarcoglycan-sarcospan interactions. Hum Mol Genet 9:2019-2027

187. Ohlendieck K et al (1991) Dystrophin-related protein is localized to neuromuscular junctions of adult skeletal muscle. Neuron 7:499-508

188. Peng HB et al (1999) Acetylcholinesterase clustering at the neuromuscular junction involves perlecan and dystroglycan. J Cell Biol 145:911-921

189. Fuhrer C et al (1999) Roles of rapsyn and agrin in interaction of postsynaptic proteins with acetylcholine receptors. J Neurosci 19:6405-6416

190. Gautam M et al (1995) Failure of postsynaptic specialization to develop at neuromuscular junctions of rapsyn-deficient mice. Nature 377:232-236

191. Claudepierre T et al (2000) Characterization of the intermolecular associations of the dystrophin-associated glycoprotein complex in retinal Muller glial cells. J Cell Sci 113:3409-3417

192. Rurak J et al (2007) Distribution of potassium ion and water permeable channels at perivascular glia in brain and retina of the Large(myd) mouse. J Neurochem 103:1940-1953 